\title{
Volatile organic compound detection as a potential means of diagnosing cutaneous wound infections
}

DOI:

10.1111/wrr.12563

\section{Document Version}

Accepted author manuscript

Link to publication record in Manchester Research Explorer

\section{Citation for published version (APA):}

Ashrafi, M. H., Bates, M., Baguneid, M., Alonso-Rasgado, M. T., Richardson, R., \& Bayat, A. (2017). Volatile organic compound detection as a potential means of diagnosing cutaneous wound infections. Wound Repair and Regeneration. https://doi.org/10.1111/wrr.12563

\section{Published in:}

Wound Repair and Regeneration

\section{Citing this paper}

Please note that where the full-text provided on Manchester Research Explorer is the Author Accepted Manuscript or Proof version this may differ from the final Published version. If citing, it is advised that you check and use the publisher's definitive version.

\section{General rights}

Copyright and moral rights for the publications made accessible in the Research Explorer are retained by the authors and/or other copyright owners and it is a condition of accessing publications that users recognise and abide by the legal requirements associated with these rights.

\section{Takedown policy}

If you believe that this document breaches copyright please refer to the University of Manchester's Takedown Procedures [http://man.ac.uk/04Y6Bo] or contact uml.scholarlycommunications@manchester.ac.uk providing relevant details, so we can investigate your claim.

\section{OPEN ACCESS}




\section{WOUND REPAIR \\ AND \\ REGENERATION}

\section{Volatile organic compound detection as a potential means of diagnosing cutaneous wound infections}

\begin{tabular}{|r|l|}
\hline Journal: & Wound Repair and Regeneration \\
\hline Manuscript ID & WRR-17-03-0062.R1 \\
\hline Danuscript Type: & Perspective Article \\
\hline Complete List of Authors: & $\begin{array}{l}\text { Ashrafi, Mohammed; University of Manchester, } \\
\text { Bates, Matthew; MCBA Consulting } \\
\text { Baguneid, Mohamed; University Hospital of South Manchester, Vascular } \\
\text { Surgery } \\
\text { Rasgado, Teresa; University of Manchester, Bioengineering group } \\
\text { Rautemaa-Richardson, Riina; University of Manchester } \\
\text { Bayat, Ardeshir; University of Manchester, Plastic \& Reconstructive Surgery } \\
\text { Research }\end{array}$ \\
\hline Key Words: & volatile organic compound, skin, infection, cutaneous wounds \\
\hline \multicolumn{2}{|c}{} \\
\hline
\end{tabular}

SCHOLARONE ${ }^{m}$

Manuscripts 


\title{
Volatile organic compound detection as a potential means of
}

\section{diagnosing cutaneous wound infections}

Mohammed Ashrafi MB $\mathrm{ChB}^{1,3,4}$, Matt Bates $\mathrm{MChem}^{2}$, Mohamed Baguneid $\mathrm{MD}^{3}$, Teresa Alonso-

Rasgado $\mathrm{PhD}^{4}$, Riina Rautemaa-Richardson $\mathrm{MD} \mathrm{PhD}^{5}$, Ardeshir Bayat $\mathrm{MB} \mathrm{BS} \mathrm{PhD}^{*}, 1,4$

${ }^{1}$ Plastic and Reconstructive Surgery Research, Centre for Dermatological Research, Institute of Inflammation and Repair, University of Manchester, UK

${ }^{2}$ MCBA Consulting, Cardiff, UK.

${ }^{3}$ University Hospital South Manchester NHS Foundation Trust, Wythenshawe Hospital, Manchester, UK

${ }^{4}$ Bioengineering Group, School of Materials, University of Manchester, UK

\author{
${ }^{5}$ Manchester Academic Health Science Centre, Institute of Inflammation and Repair, University of \\ Manchester; and University Hospital of South Manchester, Wythenshawe Hospital, Manchester, UK \\ *Corresponding author at: Dr Ardeshir Bayat, Associate Professor, Institute of Inflammation \& \\ Repair, Stopford Building, Manchester M13 9PT, UK. Tel: +44 1613060607. \\ E-mail address: ardeshir.bayat@manchester.ac.uk
}

Running title: VOC detection and wound infection diagnosis

Keywords: Cutaneous wounds; volatile organic compound; skin; infection 


\begin{abstract}
Chronic cutaneous wound infections and surgical site infections (SSIs) present a huge burden on the healthcare system and can lead to increased morbidity and mortality. Current diagnostic methods of identifying and confirming infection involve culture-based and molecular methods. Both techniques are time consuming and delays commonly lead to untargeted empirical treatment. An ideal diagnostic method would be non-invasive and highly sensitive and detect pathogenic organisms with a high degree of accuracy in order to allow targeted treatment. Volatile organic compounds (VOCs) are a diverse group of carbon-based molecules produced and released by humans and microorganisms. VOC detection has the potential in aiding cutaneous wound infection diagnostics using non-invasive and timeefficient methods. This review provides a comprehensive update on VOCs produced and emitted by bacteria commonly associated with chronic wounds and SSIs. VOC sampling has the advantage of being painless, time-efficient, non-invasive and reproducible. VOCs emitted by these organisms are diverse. In vitro studies have identified potential signature volatile profiles, which can be used in detecting these microorganisms. Combining these profiles with volatile profiles emitted from acute, chronic and surgical wounds in vivo could potentially allow identification of bacterial-specific VOCs. VOC detection has the potential for a relatively inexpensive, portable, non-invasive and reliable clinical diagnostic tool, which could be used in detecting cutaneous wound infections and guiding their optimal management.
\end{abstract}




\section{Introduction}

Chronic cutaneous wounds occur as a result of deficiencies in wound healing processes ${ }^{1,2}$. Chronic wounds have a major impact on patient's quality of life and present a huge burden on the healthcare system ${ }^{3,4}$. Persistent cutaneous wound infection is a major contributor to delayed wound healing ${ }^{5,6}$. Cutaneous infection following post-surgical intervention is also of clinical concern. Surgical site infections (SSIs) are common complications after surgery and can lead to increased morbidity and mortality ${ }^{7,8}$. Common bacterial pathogens associated with chronic as well as superficial and deep SSIs include Staphylococcus aureus, Staphylococcus epidermidis, Escherichia coli, Pseudomonas aeruginosa, Streptococcus pyogenes and Enterococcus faecalis ${ }^{9-12}$. Current diagnostic methods of identifying and confirming cutaneous infections involve culture-based and molecular methods. Both techniques are time consuming, and culture-based methods have limited sensitivity and are susceptible to over-estimation of skin commensals leading to incorrect causative bacterial identification ${ }^{13-15}$. Delays in diagnostics often result in the use of untargeted empirical treatment with a risk for sub-optimal choice of antibiotics, the development of antibiotic resistance and increase in mortality ${ }^{16}$. An ideal diagnostic method would be non-invasive and highly sensitive and detect pathogenic organisms with a high degree of accuracy in order to allow targeted treatment.

Volatile organic compounds (VOCs) are a diverse group of carbon based molecules, including alcohols, isocyanates, ketones, aldehydes, hydrocarbons and sulphides, which are volatile at ambient temperatures ${ }^{17,18}$. VOC sampling has the advantage of being painless, non-invasive and reproducible. A compendium of VOCs emanating from the human body has been compiled with 1840 VOCs assigned from breath (872), saliva (359), blood (154), 
milk (256), skin secretions (532) urine (279), and faeces (381) ${ }^{19}$. There is increasing evidence that VOCs or combinations of VOCs are unique to various disease states and their early detection could represent a useful means of diagnosis. VOCs have been identified as potential biomarkers in malignancies of the lung ${ }^{20}$, stomach ${ }^{21}$, head and neck ${ }^{22}$, breast ${ }^{23}$, liver ${ }^{24,25}$ colon and prostate ${ }^{26}$. They have also been detected as markers of asthma ${ }^{27-29}$, chronic obstructive pulmonary disease ${ }^{30,31}$, inflammatory bowel disease ${ }^{32,33}$ and diabetes ${ }^{34,}$ 35. Microorganisms produce and release VOCs and currently volatile detection via breath testing has been at the forefront in the potential of this technology to diagnose infection ${ }^{36}$. The ability to identify VOCs in cutaneous wound infections could lead to a non-invasive and time efficient method of diagnosis.

The aim of this review is to provide a detailed update on VOCs produced and emitted by bacterial species commonly associated with cutaneous wound infections. It then describes the volatile profile of skin in health and disease. Finally, the role of volatile detection from cutaneous wounds is discussed. An extensive literature search was conducted on PubMed for relevant articles published from 1960 onwards. MeSH terms used included a variety of combinations including: SSI, surgical wound infection, VOCs, biofilm, staphylococcus, Escherichia coli, streptococcus, enterococcus, Pseudomonas aeruginosa, gram positive bacteria, gram negative bacteria, wound infection, post-operative wound infection, wound healing and skin. 


\section{Chronic wounds and SSIs}

Chronic wounds represent a major burden on patients with the National Health Service expenditure in managing these wounds in excess of $£ 1$ billion annually ${ }^{3}$. Biofilms are present in more than half of chronic wounds and present a major obstacle in healing ${ }^{37}$. Over 50 million in-patient surgical procedures are performed in the USA annually with approximately $1-5 \%$ developing SSIs with a high associated mortality ${ }^{38,39}$. SSIs pose a significant burden on the healthcare system leading to increase postoperative in-patient stay, increased expenses and readmissions. The preliminary management of SSIs involves preventative measures which include but are not limited to peri-operative antibiotics and meticulous skin preparation prior to the procedure. However, despite these measures SSIs represent the most common hospital acquired infections in surgical patients ${ }^{40}$. Risk factors associated with SSIs include patient and operative factors. Patient factors include diabetes, obesity, smoking and preoperative active infection ${ }^{41-43}$. Operative factors include wound characteristics which can be classified into four categories, namely, clean, clean-contaminated, contaminated and dirtyinfected ${ }^{44}$. An escalating risk of developing SSIs is linked to the level of wound characterisation ranging from $1.3 \%$ for clean wounds to $40 \%$ for dirty-infected wounds ${ }^{45,46}$. Other operative factors include preoperative showering and hair removal, hand-washing and surgical attire, and intra-operative skin preparation ${ }^{47}$.

Planktonic bacteria undergo a four phase cycle of growth consisting of a lag phase, log phase, stationary phase and death phase. Biofilms are physiologically distinct from their planktonic counterparts and undergo a different developmental cycle, which involves initial attachment to the surface, irreversible attachment, maturation and dispersion ${ }^{48}$. Biofilms are more prevalent than expected in surgical wounds with up to $80 \%$ of SSIs involving the presence of 
SSIs are classified into three categories: superficial incisional where the infection occurs around the area of the skin where the incision was made; deep incisional where the infection occurs deep to the incision effecting the underlying fascia and muscle; and organ/space where the infection effects the organs or body cavities ${ }^{44}$. We propose the potential use of volatile detection as a means of diagnosing SSIs would be limited to superficial SSI and potentially deep SSI as these would allow the non-invasive capture of VOCs. The most typical causative micro-organisms of superficial and deep SSIs are pathogens native to the patient's skin which include staphylococci, streptococci, enterococci and gram negative bacilli ${ }^{47}$. 


\section{Microorganisms and VOCs}

A portion of normal microbial metabolites produced are VOCs ${ }^{58}$. They are thought to evolve as products or by-products of metabolic pathways ${ }^{59}$. Zoller and Clark were the first to report laboratory evidence of bacterial production of volatiles ${ }^{60}$. Many classification systems exist for microbial volatiles with one potential system categorising them Bacterial volatiles can be elassified-into fatty acid derivatives, aromatic compounds, nitrogen-containing compounds, sulphur compounds, terpenoids, halogenated selenium, tellurium and other metalloid compounds ${ }^{61}$. Their production is dependent on the bacterial species, bacterial strains, and its bacterial growth phase, co-cultures, $\mathrm{pH}$, humidity, nutrients-and ${ }_{2}$ temperature and other environmental factors ${ }^{62,63}$. The ability to rapidly sample and analyse VOCs, potentially allowing identification of bacteria, has massive implications in the management of infection in clinical settings. 


\title{
VOC sampling and analytical techniquesVOCs produced by mieroorganisms commonly
} associated with wound infection

There are numerous sampling (figure 1) and analytical (figure 2)-techniques that have been utilised in order to collect and identify VOCs, the advantages and limitations of which are outlined in Figure 1s produced and emitted by microorganisms. These include VOC collection onto adsorbents, such as Tenax or solid-phase micro-extraction (SPME) ${ }^{64}$, either directly or through an intermediary such as gauze or cotton pads ${ }^{65}$; collection in sealed containers ${ }^{66}$; direct or indirect solvent extraction ${ }^{67}$; or combinations of the above. The above methods do not often identify all VOCs present due to selective adsorption of the trapping material and these sampling techniques limit accurate quantification of VOCs and therefore $\underline{\text { direct sampling are utilised }}^{68}$.

This section details the VOCs identified from the common causative bacteria of wounds based on the different sampling and analytical techniques available.

\begin{abstract}
Studies haveThere are a-used a variety of methodological and-analytical chemical techniques used in VOC detection (Figure 2). Gas chromatography mass spectrometry (GCMS) is a combined analytical system and is one of the most widely used and powerful analytical chemical methods. It detects and quantifies VOCs over a range from parts per million to part per billion or less. Samples for GCMS must be in the gaseous phase where they are injected into the chromatograph where an inert carrier gas transports it though a tubular column. The length of the columns used varies with longer columns providing better chromatographic resolution and maximum separation of analytes. Each compound is emitted from the column at different times with the mass spectrometer used to detect eluting compounds through compound ionisation followed by measurement of the mass to charge ratio of each ion
\end{abstract}


generating a unique mass spectrum for the compound ${ }^{69}$. The major advantages of GCMS are increased sensitivity and compound identification is greatly facilitated by the availability of extensive and easily searchable databases ${ }^{70}$. However, it is not typically strong at identifying unknown compounds. Other limitations of GCMS are increased processing and analysis times and similarity of molecular fragmentation patterns from structural isomers can make compound identification difficult ${ }^{71}$. Also, due to high detection limits, sample preconcentration using techniques described above are typically required, making quantification of VOCs very difficult. A time of flight (TOF) mass spectrometer serves a very similar purpose to GCMS with the exception of providing a combination of high mass accuracy and $\underline{\text { extended range of detectable metabolites }}^{72}$.

Ion mobility spectrometry (IMS) separates gas-phase ions based on their size and shape ${ }^{73}$. This technology has long been used in the detection of explosives and illegal substances ${ }^{74}$. It can be coupled to a pre-separating multi capillary column (MCC) unit allowing two$\underline{\text { dimensional volatile separation, significantly increasing the resolution of metabolites }}^{75}$. MCC allows minimisation or avoidance of analyte interactions in the ionisation region of the IMS, thus reducing the complexity of the measurement signal ${ }^{76}$. IMS is advantageous over GCMS as ambient air can be used as the carrier gas, eliminating the need for a pure speciality inert gas or a vacuum. This has allowed IMS to be portable and provide on-site measurements. IMS is highly sensitive with very low detection limits between the parts per billion to parts per trillion ranges, offers excellent low detection limits and gives relatively rapid results ${ }^{77}$. IMS is however not suitable for identification of unknown compounds. 
Direct injection mass spectrometry methods include ion molecule reaction mass spectrometry (IMR-MS), secondary electrospray ionisation mass spectrometry (SESI-MS), selected ion flow tube mass spectrometry (SIFT-MS) and proton transfer reaction mass spectrometry (PTR-MS). A drawback of conventional mass spectrometry instrumentation is the high fragmentation of molecules in a complex gas mixture secondary to high electron ionisation leading to complex mass spectra with overlapping intensities, thus making quantification difficult or impossible. IMR-MS offers a very soft from of ionisation leading to less fragmentation. SESI-MS utilises electrospray ionisation technique in order to produce analytes suitable for mass analysis. In PTR-MS, compounds are ionised via proton transfer prior to analysis. This involves the production of $\mathrm{H}_{3} 0^{+}$ions from high purity distilled water through a cathode ion source. SIFT-MS is similar to PTR-MS but is able to ionise a wider $\underline{\text { range of analytes as it uses a greater number of precursor ions }\left(\mathrm{H}_{3} 0^{+}, \mathrm{NO}^{+} \text {or } \mathrm{O}_{2}^{+}\right.} \underset{ }{+}$ for chemical ionisation ${ }^{69}$. The major advantage of direct injection methods is quantification. These direct methods also have lower detection limits than GCMS at parts per trillion ranges. They also provide real-time detection with no sample preparation or separation requirements. They are however limited in the range of VOCs detected compared to GCMS and PTR-MS is limited to the identification of compounds with a higher proton affinity than water.

The electronic nose devices constitute a non-invasive technique capable of detecting and differentiating VOC patterns based on its ability to detect odour. The Cyranose 320 and E50835 electronic nose devices have been used in bacterial identification. These devices allow imprinting of an odour on its sensor chip micro-array which is composed of complex materials. When the sensors are exposed to a gas, the polymer absorbs the gas and swells, during which the distance between the conductive carbon particles increases and thus also $\underline{\text { increases the resistance of the sensor material }}^{78}$. This change in resistance is transmitted to a 
computer with the pattern of change in the sensor array being used to detect the gas. Electronic nose devices are powerful at differentiating between non-identical samples, provide rapid results with on-site sampling. They are however limited due to temperature and humidity sensitivity, only detect patterns of VOCs programmed on their database and are not suitable for screening of unknown compounds.

Formatted: Font:

, therefore using very specific search criteria were abandoned as this would have led to exclusion of a large proportion of studies. With regards to VOC quantities, studies varied with some presenting relative abundances whereas others identified absolute concentrations of compounds and therefore quantitative analysis was not possible. The majority of studies have provided VOC abundances relative to other compounds identified (79-84). Studies where absolute abundances of VOCs are shown range from the parts per million volume to parts per trillion volume $(85-87)$. Parts per million volume concentrations equate to $\mu \mathrm{g} / 1$ sampled, parts per billion volume concentrations equate to $\mathrm{ng} / \mathrm{l}$ sampled and parts per trillion volume concentrations equate to pg/1 sampled. Studies in which more than 5 VOCs were identified for a specific bacterial species, only the top 5 -compounds based on abundance (either relative or absolute) are presented (table 1). Studies where VOC production could not be attributed to an isolated bacterial species or strain were excluded.

Informatics approaches also varied between the studies evaluated. Four main methods were used to confirm identification of VOCs. Some studies compared mass spectra to reference libraries and databases, such as the National Institute of Standards and Technology (NIST) (83, 88), Wiley (89) and Massbank (90) libraries and pre-determined reference databases (91). Other studies compared mass spectra and peak retention times with those obtained from pure standard compounds $(82,85,92)$. The majority of studies combined the use of reference 
libraries and pure standard compounds for identification of VOCs $(79,81,86,87,89,93$-97). A third technique used was the manual comparison of mass spectra with those available in the literature (94). Lastly, due to the limitations of certain analytical techniques in compound identification, concurrent techniques were utilised to confirm VOC identity (76, 98 101).

\section{$\underline{\text { VOCs produced by microorganisms commonly associated with wound infection }}$}

This section details the VOCs identified from the common causative bacteria of wounds based on the different analytical techniques available. With regards to VOC quantities, based on analytical technique used studies varied with some presenting relative abundances whereas others identified absolute concentrations of compounds. The majority of studies have provided VOC abundances relative to other compounds identified ${ }^{79-84}$. Studies where absolute abundances of VOCs are shown range from the parts per million volume to parts per trillion volume ${ }^{85-87}$. Parts per million volume concentrations equate to $\mu \mathrm{g} / \mathrm{l}$ sampled, parts per billion volume concentrations equate to $\mathrm{ng} / \mathrm{l}$ sampled and parts per trillion volume concentrations equate to $\mathrm{pg} / 1$ sampled. Studies in which more than 5 VOCs were identified for a specific bacterial species, only the top 5 compounds based on abundance (either relative or absolute) are presented (table 1). Studies where VOC production could not be attributed to an isolated bacterial species or strain were excluded.

Informatics approaches also varied between the studies evaluated. Four main methods were used to confirm identification of VOCs. Some studies compared mass spectra to reference $\underline{\text { libraries and databases, such as the National Institute of Standards and Technology (NIST) }}{ }^{83}$, ${ }^{88}$. Wiley ${ }^{89}$ and Massbank ${ }^{90}$ libraries and pre-determined reference databases ${ }^{91}$. Other studies compared mass spectra and peak retention times with those obtained from pure $\underline{\text { standard compounds }}^{82,85,92}$. The majority of studies combined the use of reference libraries 
GCMS has been the main analytical method utilised to identify VOCs. Neerincx et al inoculated $P$. aeruginosa in brain heart infusion broth and sampled the headspace using glass tubes filled with-Tenax TA at 16, 24 and 48 hours ${ }^{93}$. The top 5 VOCs emitted from $P$. aeruginosa cultures were methyl thiolacetate, 2,3-dimethyl-5-isopentylpyrazine, 2-methyl-3(2-propenyl)-pyrazine, 3-methyl-1 H-pyrrole and 6-tridecane. Scholler et al sampled volatile metabolites emitted from $P$. aeruginosa eultured in Autoinducer Bioassay medium by diffusive sampling again using using stainless steel analytical thermal desorption tubes packed with mesh-Tenax ${ }^{89}$. The major headspace VOC identified was dimethyl disulphide with isoprene, dimethyl trisulphide and 1 - undecene also detected. Bean et al were the first to report the application of two-dimensional GC-TOF spectrometry to identify volatiles of $P$. aeruginosa grown for 24 hours in lysogeny broth in sealed GC headspace vials via SPME passive sampling ${ }^{88}$. This method facilitated the identification of 56 VOCs emitted by $P$. aeruginosa of which 28 were new including alcohols, heteroaromatics, ketones, benzenes and aldehydes $^{88}$. Scott-Thomas et al used similar SPME sampling of the headspace of $P$. aeruginosa and found high concentrations of 2-aminoacetophenone ${ }^{84}$. 
Indole is produced by both pathogenic and non-pathogenic strains of $E$. coli cultured on a mixture of trypticase soy agar and brain heart infusion broth ${ }^{86}$. This was demonstrated by analysing the headspace of these cultures using a Super $Q$ porous polymer trapping method (86). Bianchi et al inoculated commercial tins of peeled tomatoes with E. coli and found and collected headspace gas via a glass tube trap filled with Tenax TA at day 2 and 7 (81). They found-the most abundant compounds detected were dimethylsulfide, 6-methyl-5-hepten-2one, ethanol, ethyl acetate and 3-methyl furan_ ${ }^{81}$. Umber et al identified differing volatile signatures of $E$. coli dependant on the environment. Headspace analysis revealed E. coli inoculated whole blood released a different set of VOCs compared to E. coli cultured in Luria Bertani (LB) broth ${ }^{85}$. VOCs specific to E. coli-infected whole blood were dimethyl sulfide, carbon disulphide, ethanol, acetaldehyde and methyl butanoate. Whereas dimethyl disulfide, dimethyl trisulfide, methyl propanoate, 1-propanol and methylcyclohexane were isolated only from E.coli cultured in LB broth ${ }^{85}$.

Filipiak et al cultured $S$. aureus and $P$. aeruginosa in tryptic soy broth medium and collected the-headspace samples on multi-bed sorption tubes at differing time intervals for up to 28 
hours ${ }^{87}$. S. aureus released 32 VOCs and P. aeruginosa 37 of diverse chemical classes at different concentrations - comprising aldehydes, alcohols, ketones, acids, sulphur containing compounds, esters, hydrocarbons and nitrogen containing compounds. They found distinct differences in the bacteria-specific VOC profiles, especially with regard to aldehydes-(2 methylpropanal, acetaldehyde, 3 -methylbutanal, (Z) 2 methyl 2 butenal), which were released-observed by $S$. aureus with no release observed from P. aeruginosa ${ }^{87}$. Preti et al sampled the headspace of $P$. aeruginosa and $S$. aureus cultured in blood agar medium in petri culture dishes and identified compounds specific to each species ${ }^{94}$.

\section{Zscheppank (82)-et al utilised a novel needle trap technique consisting of a sorbent packed needlea novel technique of needle trap to sample the headspace of $E$. coli and P. aeruginosa cultured in liquid media-over a 48 hour period. Needle trap is an extraction device that contains a sorbent packed inside of a needle ${ }^{102}$ and found- They found both organisms produced isoprene. Dimethyl sulphide, 1-undecene and 2-nonanone were specific to $P$. aenuginosa and E. coli produced carbon disulfide, butanal and indole ${ }^{82}$. \\ Elgaali et al utilised purge and trap and passive SPME sampling of the headspace to analyse E. coli and $S$. aureus ${ }^{95}$. Both sampling techniques identified indole as the principle component over the headspace of E. coli and the purge and trap technique identified long chain alcohols, 2-methylbutanol and 3-methylbutanol in abundance, whereas, passive SPME sampling of the headspace identified 2-tridecenone and dimethyldisulfide over the headspace of $S$. aureus $^{95}$.}


Gas chromatography time-of-flight mass spectrometry (GC-TOF-MS)

A time of flight mass spectrometry measures the mass-dependent time it takes ions of different masses to move from the ion source to the detector. It allows rapid detection and analysis of a wide range of smaller molecules (103). Boots et al sampled the bacterial headspace, using desorption tubes packed with carbograph 1TD/Carbopack X, of S. aureus, methicillin-resistant $S$. aureus (MRSA), P. aeruginosa and E. coli cultured in a variety of agars and broths ${ }^{83}$. Samples were analysed by GC-TOF-MS. They identified 25 VOCs which could be used to discriminate between the bacterial strains. They also found 1,1,2,2tetrachloroethane, 2-heptanone and 1,4-dichlorobenzene are differentially excreted in the headspace of $S$. aureus and $M R S A$, with the latter two compounds significantly more abundant over the headspace of $M R S A^{83}$.

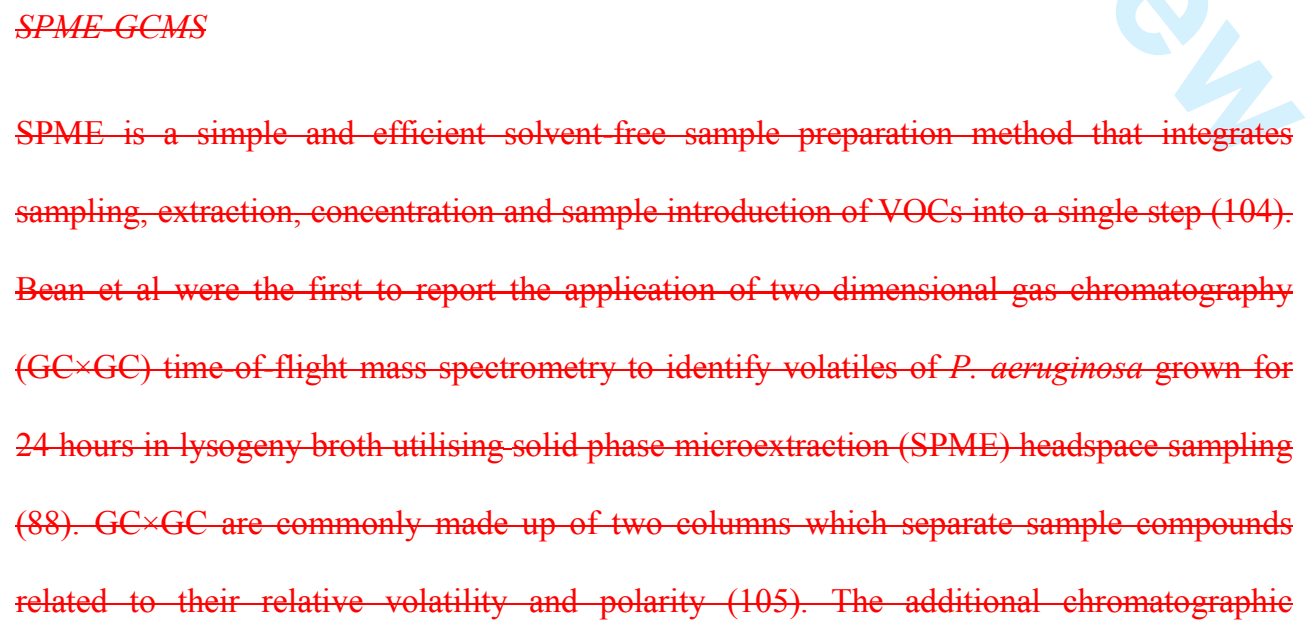


dimension improves spectral purity improving the detection of low abundance volatiles. This method facilitated the identification of 56 VOCs emitted by $P$. aeruginosa of which 28 were new including alcohols, heteroaromatics, ketones, benzenes and aldehydes (88).Scott-Thomas et al found specific to $P$. aenuginosa cultured in sheep blood agar, high concentrations of 2 aminoacetophenone in the headspace sampled using SPME at 24 hours (84). Preti et at sampled the headspace of $P$. aeruginosa and $S$. aureus cultured in blood agar medium in petri eulture dishes (94). Characteristic compounds of $S$. atreus in order of abundance were isovaleric acid, 2 methylbutyric acid, isobutyric acid, 1 hydroxy 2 propanone, 3 hydroxy 2 butanone, butyric acid, 4 methylhexanoic acid and 2 phenylethyl alcohol. For $P$. aenuginost, signature VOCs detected were 2-Amino-acetophenone, dimethyldisulfide, undecene, dimethylpyrazine and dimethylsulfide (94). Elgaali et al utilised two collection methods (porous polymer Super Q and SPME) to analyse the headspace of E. coli and S. aureus eultured in tryptic soy agar and broth (95). Both sampling techniques identified indole as the principle component over the headspace of $E$. coli and the porous polymer trapping technique identified long chain alcohols, 2 methylbutanol and 3 -methylbutanol in abundance. SPME sampling identified 2 tridecenone and dimethyldisulfide over the headspace of $S$. autreus (95). Two studies have assessed the VOCs emitted in the headspace of sputtm samples using SPME-GCMS $(106,107)$. These however did not isolate the bacterial strains and are therefore not discussed further.

\section{Multi capillary column coupled ion mobility spectrometry (MCC-IMS) \\ IMS is a portable, sensitive and time effieient instrumental analytical technique. IMS provides characterisation of organic and inorganic compounds based upon ion mobility or size-to-charge ratio rather than mass-to-charge ratio (73). It can detect very low}


eoncentrations of compounds without any pre-concentration; however it is not as powerful as GCMS in separating and identifying metabolites (108). Maddula et al utilised MCC-IMS to identify three VOCs namely, ethanol, heptan-2-one, and nonan-2-one emitted from the headspace of $E$. coli cultures which were cross-validated with SPME-GCMS ${ }^{76}$. Guaman et al evaluated IMS and SPME-GCMS in the detection of VOCs in the breath of rats injected intraperitoneally with $E$. coli or regular saline after 24 hours and found (98). They identified IMS had-IMS had a higher sensitivity and specificity than SPME-GCMS in distinguishing the two groups based on volatile analysis ${ }^{98}$. Kunze et al analysed using MCC-IMS the headspace of E. coli and P. aeruginosa cultured in Lysogeny Broth at four time points (91) and found : They found-six VOCs (Decan-1-ol, Ethanol, Indole, Octan-1-ol [monomer and dimer] and P_755_105) exclusively over the headspace of $E$. coli cultures and 7 VOCs (2-Propanone, Azane [dimer], Dodecane, 2-Ethylhexan-1-ol, P_603_25, P_648_36 and P_778_4) emitted exclusively by $P$. aeruginosa cultures, with their concentrations differing across the time points analysed ${ }_{-}^{91}$.

\section{Direct injection mass spectrometry fon molecule reation mass spectrometry (IMAR-MS)}

IMR MS provides a highly sensitive method for online and off line sampling of VOCs (109). It uses a non-fragmenting chemical ionisation mode (110) and is extremely time-efficient. Only a single study to date has utilised IMR-MS to analyse the headspace over E. faecalis, $S$. aureus and S. epidermidis cultured in blood agar and brain heart infusion broth ${ }^{92}$. They were able to differentiate between the species based on the mass spectra generated from the VOCs. 
Secondary electrospray ionisation-mass spectrometry (SESI-MS)

SESI-MS has the ability to directly sample ambient gas and provide real-time detection and analysis of VOCs (68). Zhu et al were the first to report the application of SESI-MS to the detection and characterisation of VOCs produced by P. aeruginosa, S. aureus and E. coli cultured in tryptic soy broth ${ }^{90}$. They identified P. aeruginosa emitted ethanol and 4Methylphenol in high abundance; S. aureus emitted high concentrations of butanol, acetone and acetic acid; E. coli principle emitted volatile was indole. A follow on study by the same group were able to distinguish 11 strains of E. coli from S. aureus based on VOCs ${ }^{103}$. In addition they identified $6 \mathrm{VOC}$ biomarkers that were common in all E. coli strains.

\section{Selected ion flow tube mass spectrometry (SHFT-MS) \\ SIFT-MS is rapid, has a high sensitivity for volatile detection and can detect small molecules not readily detectable by GCMS (108). It also provides quantification of VOCs and can monitor varying compound levels in real time (112). Carroll et al cultured different strains of P. aeruginosa on blood agar and pseudomonas-selective media and analysed the headspace} using SIFT-MS ${ }^{104}$. They identified the majority of strains emitted high quantities of ammonia and hydrogen cyanide compared to controls. Shestivska et al corroborated the latter findings using both SPME-GCMS and SIFT-MS ${ }^{96}$. They also identified a second compound, methyl thiocyanate, is commonly emitted from the majority of $P$. aeruginosa strains and most probably both compounds are biochemically associated. A follow on study by the same group identified differing production rates of VOC by genotypically different strains of $P$. 
Allardyce et al inoculated blood culture bottles, supplemented with tryptic soy broth, with isolated strains of P. aeruginosa, S. aureus and E. coli and analysed emitted VOCs using SIFT-MS at 6 hours ${ }^{106}$. Nine VOCs in total were assessed to differentiate between the bacterial strains. $P$. aeruginosa cultures had relatively high absolute concentrations of acetic acid and acetone; E. coli ethanol and acetaldehyde; and S. aureus ethanol and acetone ${ }^{106}$. Storer et al used SIFT-MS to measure volatiles emitted from the headspace of urine samples inoculated with P. aeruginosa, S. aureus, S. epidermidis, E. coli and E. faecalis at 6 hours ${ }^{107}$. The principle VOC emitted compared to non-inoculated samples was formaldehyde for $E$. coli, ethanol for P. aeruginosa and ammonia for S. epidermidis, S. aureus and E. faecalis. In contrast, Sovova et al found the principle volatile emitted from the headspace of E. coli cultured in nutrient broth enriched with glucose was ethanol ${ }^{108}$. This could be explained by the use of different media, strains and growth conditions between the studies. This assumption is confirmed by Chippendale et al who analysed the VOC from the headspace of E. coli cultured in two different media ${ }^{109}$. E. coli cultured in Dulbecco's modified Eagle's medium resulted in large amounts of ethanol, acetaldehyde and hydrogen sulphide production, whereas E. coli cultured in lysogeny broth, ammonia was the major volatile compound ${ }^{109}$. 


\section{Proton transfer reaction mass spectrometry (PTR-MS) \\ PTR-MS uses protonated water as a chemical ionisation reagent to measure volatiles. It is a} fast technique providing real time analysis (119). However, it is not as powerful as GCMS in separation and identification of volatiles and not all molecules are detectable. Lechner et al described the used of-PTR-MS to analyse the headspace of of bacterial cultures. They cultured $E$. coli, P. aeruginosa and S. aureus cultured in either MacConkey agar or Mannitolsalt agar 24 hours and analysed the headspace for signature volatiles- ${ }^{99}$. They identified patterns which were specific to the bacterial species however did not expand on the identity of the VOCs. Using PTR-MS, O'Hara and Mayhew analysed the headspace of S. aureus cultured in three different broths (nutrient, dextrose and brain heart bovine) and found although the VOCs emitted were specific to $S$. aureus, their concentrations differed dependant on the type of media they were grown in ${ }^{100}$. Both Luchner et al ${ }^{101}$ and Bunge et al ${ }^{110}$ have utilised PTR-MS to identify volatiles in the headspace of $E$. coli.

\section{Electronic nose}

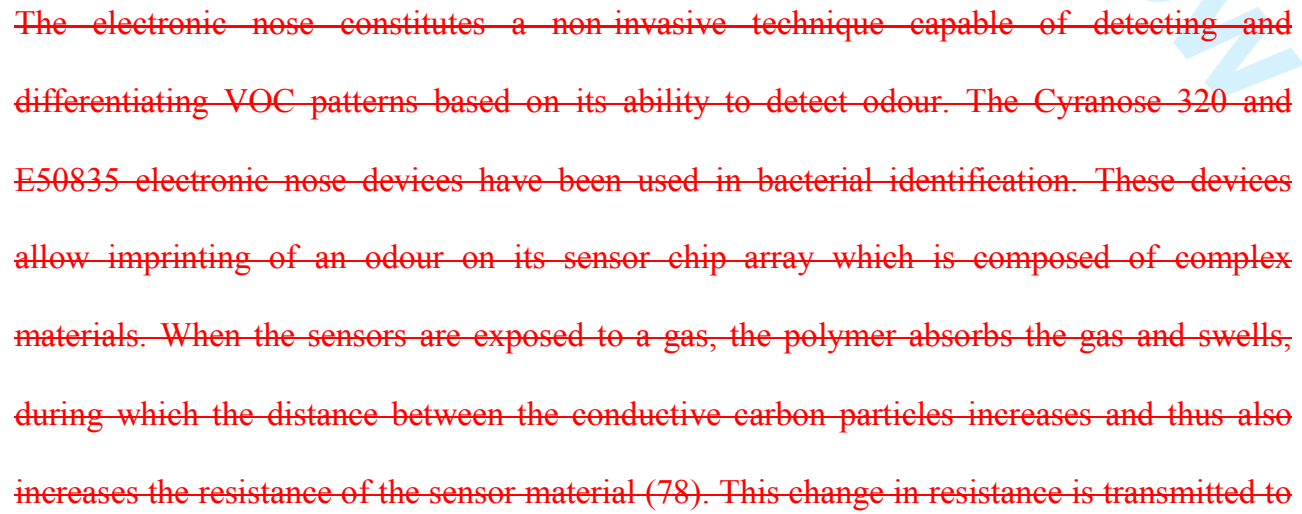



compounds emitted by the bacteria. 


\section{Skin and VOCs}

Skin is the largest human organ ${ }^{114}$ and forms an essential barrier between the body and the environment, protects from injury and provides vital homeostatic mechanisms including control of temperature, maintenance of fluid balance, and detection of sensations such as pain ${ }^{115}$. A compilation of 1840 VOCs emitted from healthy human individuals has recently been published with skin containing 532 different compounds ${ }^{19}$. The origins of VOCs emanating from skin are either from eccrine, sebaceous, and apocrine glandular secretions or metabolism of the skin microbiota ${ }^{67,116-119}$ (Ffigure 3). VOCs released from skin are diverse including ketones, aldehydes, heterocyclic compounds, hydrocarbons, terpenes, esters, volatile sulphur compounds and alcohols ${ }^{66,67,120-122}$. VOCs emitted from skin are affected by environmental factors such as diet and use of fragranced products such as soaps and perfumes 123. This makes study design difficult with studies to date varying on the protocol with regards to skin preparation prior to volatile extraction. Some have asked subjects to make no changes ${ }^{124}$, others have stipulated the avoidance of fragranced products ${ }^{67}$, whilst others have implemented dietary restrictions ${ }^{125,126}$. Studies examining the skin volatilome have employed different sampling techniques. These include solvent extraction, dynamic headspace absorption indirectly or directly onto absorbent traps, trapping tubes allowing direct insertion into the $\mathrm{GC}$ and SPME ${ }^{68,119,127-130}$. Each has their advantages and limitations including isolation of unexpected VOCs, exogenous contamination and loss of low molecular weight volatiles (Figure 1) ${ }^{64}$.

The top 5 VOCs identified from human skin are 6- methyl-5-hepten-2-one, nonanal, decanal, geranylacetone and (E)-2-nonenal ${ }^{64}$. Harraca et al analysed the VOCs of the whole human body by collection through customised heat sealed oven bags which participants wore from 
VOCs emitted from the skin have been studied as potential markers of disease. VOC patterns from skin melanoma have been identified using electronic nose devices ${ }^{135}$ and Kwak et al employed headspace SPME-GCMS to identify specific volatiles that could differentiate between melanoma and normal melanocyte cells cultured in vitro ${ }^{136}$. They found melanoma cells emit dimethyl disulfide and dimethyl trisulfide along with higher concentrations of isoamyl alcohol compared to normal melanocytes. Abaffy et al reported 3 studies utilising headspace SPME-GCMS for the differentiation of melanoma in vivo ${ }^{137-139}$. Firstly they identified 4-methyl decane, dodecane and undecane were preferentially expressed in melanoma fresh and frozen tissue samples compared to control skin ${ }^{137}$. In a follow on case study they found 32 VOCs of which 23 were only detected from melanoma lesions compared to normal skin in the same individual ${ }^{138}$. They later followed this on with a pilot study in which they recruited 5 patients with melanoma and 5 patients with benign skin lesions and found increased levels of the fatty acids lauric acid and palmitic acid in melanoma ${ }^{139}$. The detection of VOCs from skin has also been applied experimentally to detect heart failure and 
diabetes ${ }^{140,141}$. Voss et al utilised an electronic nose device to detect emitted VOCs from skin and were able to discriminate between heart failure patients and controls with an accuracy of $87 \%{ }^{140}$. Turner et al used SIFT-MS to carry out a pilot study on five volunteers to determine $\underline{\text { VOC changes from skin before and after the ingestion of glucose in the fasting state }}{ }^{141}$. VOCs were collected in a collection bag surrounding part of the arm and changes in acetone were noted post ingestion of glucose compared to the fasting state ${ }^{141}$. 


\section{Wounds, SSIs and VOCs}

There are no studies published to date investigating the use of VOC detection in the diagnosis of SSIs. The evidence of VOCs emitted from cutaneous wounds is sparse with only two in vivo studies to date. Parry et al utilised an electronic nose device which was able to differentiate between uninfected venous leg wounds and those infected with beta-Haemolytic streptococci $^{142}$. Thomas et al obtained VOC samples from 5 patients with chronic lower limb wounds using a polydimethylsilicone membrane and analysed by gas chromatography ion trap mass spectrometry ${ }^{143}$. They sampled from the wound, boundary areas around the wound and normal skin. They identified an array of VOCs which were unique to each of the sampled sites. They found significant differences in the VOC profile between normal skin and boundary skin and between normal skin and wounded skin but showed no difference between boundary skin and wound profiles. They recognised 6 compounds which may be responsible for this difference: 1-(1-methyethoxy) 2-propanol; dimethyl disulfide; 3-carene; 2-ethyl-1hexanol; 3,5-bis(1,1-dimethylethyl)-phenol; and butylated hydroxytoluene. These compounds are often associated with preservatives found in creams and gels. However, they do elucidate that their protocol restricted the use of such creams and gels and that none of the patients reported using such products during the study period. Although study numbers were small, they provided a basis on which to develop further studies to identify the role of VOCs in wound healing. Dini et al captured the volatiles emitted from compressed and noncompressed body regions using GCMS and an electronic nose device ${ }^{144}$. Their main aim was to identify if the pattern of volatiles emitted differed dependant on skin pressure which would allow the potential identification of patients at risk of developing decubitus wounds. They found emissions from compressed tissue differed from those of non-compressed tissue allowing the potential to be able to non-invasively detect those at risk of developing wounds 144 


\section{Conclusions and future perspectives}

VOCs emitted by microorganisms commonly associated with cutaneous wound infections are diverse. Studies isolating these pathogens have allowed the identification of potential signature-combinations of volatiles which would-may allow detection of their presence. Although there are many VOCs that are shared between microorganisms, there are those identified to be unique to particular bacteria (table 2). This knowledge is imperative if this technology $\mathrm{VOC}$ detection is to be developed not only to identify if a wound is infected or not but differentiate between causative microorganisms. Although it must be considered that the majority of studies have only investigated the VOC profile of a limited number of species and strains and this may not hold true when extrapolating this to significantly more species and strains.

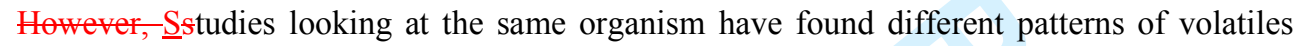
detected most probably explained by the use of different sampling methods and analytical techniques. Identifying and using the best suited sampling and analytical techniques will be critical. Although there is a wide spectrum of VOCs attributed to the presence of bacteria such as $P$. aeruginosa and E. coli, there is paucity in information available with regards to others such as MRSA, E. faecalis and S. pyogenes. Also of note is that the methodology of the studies thus far employed the use of various media and broths which are not ideal models for skin and cutaneous wounds. Therefore, one must be wary of inferring which volatiles will be emitted by organisms in skin and wounds by extrapolating the findings from these studies. Also, the in vitro studies discussed above have all identified VOCs specific to bacterial species in the planktonic phase. Extrapolating this to the identification of the bio-burden in a biofilm state must be approached with caution as the presence of other biofilm components 
such as the extracellular polymeric substance may alter the VOC profile. Therefore, future studies must compare the VOC profiles of bacterial species in both their planktonic and biofilm states.

In vivo studies assessing VOCs released from skin have identified a vast array of volatiles in both health and disease with potential markers of cutaneous malignancy and other common diseases identified. However, studies again have varied with regards to sampling methods which have proved much more difficult compared to in vitro experimental sampling. Also, controlling for external factors have proven difficult in human subjects leading to identification of exogenous and contaminant VOCs despite robust attempts to minimise this. Information with regards to VOCs emitted from cutaneous wounds is very limited; however the couple of studies to date have provided a direction for future work.

Current laboratory-based techniques - culture and non-culture based techniques - are timeconsuming and culture over-estimates rapidly dividing non-fastidious bacteria and underestimates more fastidious anaerobes ${ }^{50}$. Molecular methods provide a detailed breakdown of the poly-microbial nature of wounds, however, are deficient in providing information regarding the dominant strain or strains driving the infection. Therefore, the use of untargeted empirical antimicrobial treatment is common based on the limited strain information available, which causes delay in optimal wound management as well as risk for development of antimicrobial resistance. The addition of VOC profiling could provide a more detailed outlook on the development state of a biofilm and on the metabolic processes microorganisms are relying on to thrive in the wound, thus allowing treatment to be specifically tailored. 
With regards to utilising VOC detection techniques in the diagnosis of chronic wound and SSIs, several limitations must be considered. As described above surgical patients undergo risk reducing measures such as peri- and post-operative antimicrobial administration and surgical skin preparation which will alter the wound microbiome. This in turn will alter the microbial metabolites produced and emitted from the wound surface. Also the use of cosmetic and sanitary products which themselves will release VOCs have the potential to interfere and mis-lead. Other significant limitations are the spectrum of surgical wounds ranging from clean to dirty-infected and the phase of bacterial growth will provide a spectrum of microorganisms and therefore a substantially variable array of metabolites produced. Also most chronic wounds are poly-microbial in nature with the presence of different strains of the

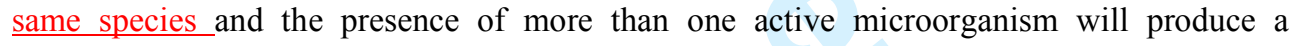
different volatile signature compared to its isolated state. Therefore it is vital that any technology introducedtechnique used has the capability to detect a multitude of VOCs and the ability to identify poly-microbial infections in order to aid specificity in diagnoses of SSIs.

There are currently no approved tests based on VOC detection in the diagnosis of SSI or cutaneous wound infections. However, there are FDA approved devices available in the diagnosis of asthma ${ }^{145}$, Helicobacter pylori infection ${ }^{146}$ and heart transplant rejection ${ }^{147}$, which are all based on VOC detection technology. There is currently a huge interest and a developing body of work in the use of VOC detection in the diagnosis and monitoring of various diseases ranging from infection to malignancy ${ }^{148,149}$. Volatile detection via breath 
We propose the need for further in vitro experimental work and robust clinical studies in order to identify signature volatiles of the common organisms attributed to the aetiology of chronic wounds and SSIs. Culturing these bacteria on skin explants and combining these with substrates such as Matrigel ${ }^{154}$ to allow representation of cutaneous wounds in vitro would allow a more accurate determination of VOCs produced and emitted. Taking this information with volatiles emitted from acute, chronic and surgical wounds in vivo would potentially allow identification of VOCs which could be attributed to infected wounds and normal and abnormal wound healing. The ultimate goal would be to develop a clinical diagnostic tool 
1

2

3

4

5

6

7

8

9

10

11

12

13

14

15

16

17

18

19

20

21

22

23

24

25

26

27

28

29

30

31

32

33

34

35

36

37

38

39

40

41

42

43

44

45

46

47

48

49

50

51

52

53

54

55

56

57

58

59

60 which is inexpensive, portable, non-invasive, and reliable and offers time efficient results in detecting cutaneous wound infections in order to expedite accurate management. VOC detection has the potential to offer this.

31 
1

2

3

4

5

6

7

8

9

10

11

12

13

14

15

16

17

18

19

20

21

22

23

24

25

26

27

28

29

30

31

32

33

34

35

36

37

38

39

40

41

42

43

44

45

46

47

48

49

50

51

52

53

54

55

56

57

58

59

60

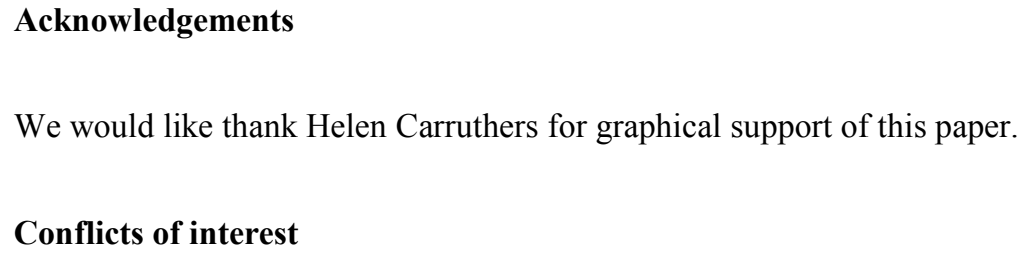




\section{References}

1. Guo S, Dipietro LA. Factors affecting wound healing. J Dent Res 2010; 89:219-29.

2. Fonder MA, Lazarus GS, Cowan DA, Aronson-Cook B, Kohli AR, Mamelak AJ. Treating the chronic wound: A practical approach to the care of nonhealing wounds and wound care dressings. J Am Acad Dermatol 2008; 58:185-206.

3. Posnett J, Franks PJ. The burden of chronic wounds in the UK. Nurs Times 2008; 104:44-5.

4. Martin-Granados C, McCaig CD. Harnessing the Electric Spark of Life to Cure Skin Wounds. Adv Wound Care (New Rochelle) 2014; 3:127-38.

5. Penhallow K. A review of studies that examine the impact of infection on the normal wound-healing process. J Wound Care 2005; 14:123-6.

6. Costerton JW, DeMeo P. Discussion. The role of biofilms: are we hitting the right target? Plast Reconstr Surg 2011; 127 Suppl 1:36S-7S.

7. de Lissovoy G, Fraeman K, Hutchins V, Murphy D, Song D, Vaughn BB. Surgical site infection: incidence and impact on hospital utilization and treatment costs. Am J Infect Control 2009; 37:387-97.

8. Mangram AJ, Horan TC, Pearson ML, Silver LC, Jarvis WR. Guideline for prevention of surgical site infection, 1999. Hospital Infection Control Practices Advisory Committee. Infect Control Hosp Epidemiol 1999; 20:250-78; quiz 79-80.

9. Giacometti A, Cirioni O, Schimizzi AM, Del Prete MS, Barchiesi F, D'Errico MM, et al. Epidemiology and microbiology of surgical wound infections. J Clin Microbiol 2000; 38:918-22.

10. Saini S, Gupta N, Aparna, Lokveer, Griwan MS. Surgical infections: a microbiological study. Braz J Infect Dis 2004; 8:118-25.

11. Surucuoglu S, Gazi H, Kurutepe S, Ozkutuk N, Ozbakkaloglu B. Bacteriology of surgical wound infections in a tertiary care hospital in Turkey. East Afr Med J 2005; 82:331-6.

12. Múñez E, Ramos A, Espejo T, Vaqué J, Sánchez-Payá J, Pastor V, et al. [Microbiology of surgical site infections in abdominal tract surgery patients]. Cir Esp 2011; 89:606-12.

13. Grace CJ, Lieberman J, Pierce K, Littenberg B. Usefulness of blood culture for hospitalized patients who are receiving antibiotic therapy. Clin Infect Dis 2001; 32:1651-5.

14. Bates DW, Goldman L, Lee TH. Contaminant blood cultures and resource utilization. The true consequences of false-positive results. JAMA 1991; 265:365-9.

15. Pletz MW, Wellinghausen N, Welte T. Will polymerase chain reaction (PCR)-based diagnostics improve outcome in septic patients? A clinical view. Intensive Care Med 2011; 37:1069-76.

16. Retamar P, Portillo MM, López-Prieto MD, Rodríguez-López F, de Cueto M, García MV, et al. Impact of inadequate empirical therapy on the mortality of patients with bloodstream infections: a propensity score-based analysis. Antimicrob Agents Chemother 2012; 56:472-8.

17. Zlatkis A, Brazell RS, Poole CF. The role of organic volatile profiles in clinical diagnosis. Clin Chem 1981; 27:789-97.

18. Probert CS, Ahmed I, Khalid T, Johnson E, Smith S, Ratcliffe N. Volatile organic compounds as diagnostic biomarkers in gastrointestinal and liver diseases. J Gastrointestin Liver Dis 2009; 18:337-43. 
19. de Lacy Costello B, Amann A, Al-Kateb H, Flynn C, Filipiak W, Khalid T, et al. A review of the volatiles from the healthy human body. J Breath Res 2014; 8:014001.

20. Hakim M, Broza YY, Barash O, Peled N, Phillips M, Amann A, et al. Volatile organic compounds of lung cancer and possible biochemical pathways. Chem Rev 2012; 112:5949-66.

21. Xu ZQ, Broza YY, Ionsecu R, Tisch U, Ding L, Liu H, et al. A nanomaterial-based breath test for distinguishing gastric cancer from benign gastric conditions. Br J Cancer 2013; 108:941-50.

22. Hakim M, Billan S, Tisch U, Peng G, Dvrokind I, Marom O, et al. Diagnosis of head-and-neck cancer from exhaled breath. Br J Cancer 2011; 104:1649-55.

23. Phillips M, Cataneo RN, Saunders C, Hope P, Schmitt P, Wai J. Volatile biomarkers in the breath of women with breast cancer. J Breath Res 2010; 4:026003.

24. Amal H, Ding L, Liu BB, Tisch U, Xu ZQ, Shi DY, et al. The scent fingerprint of hepatocarcinoma: invitro metastasis prediction with volatile organic compounds (VOCs). Int J Nanomedicine 2012; 7:4135-46.

25. Xue R, Dong L, Zhang S, Deng C, Liu T, Wang J, et al. Investigation of volatile biomarkers in liver cancer blood using solid-phase microextraction and gas chromatography/mass spectrometry. Rapid Commun Mass Spectrom 2008; 22:1181-6.

26. Peng G, Hakim M, Broza YY, Billan S, Abdah-Bortnyak R, Kuten A, et al. Detection of lung, breast, colorectal, and prostate cancers from exhaled breath using a single array of nanosensors. Br J Cancer 2010; 103:542-51.

27. Olopade CO, Zakkar M, Swedler WI, Rubinstein I. Exhaled pentane levels in acute asthma. Chest 1997; 111:862-5.

28. Paredi P, Kharitonov SA, Barnes PJ. Elevation of exhaled ethane concentration in asthma. Am J Respir Crit Care Med 2000; 162:1450-4.

29. Montuschi P, Corradi M, Ciabattoni G, Nightingale J, Kharitonov SA, Barnes PJ. Increased 8isoprostane, a marker of oxidative stress, in exhaled condensate of asthma patients. Am J Respir Crit Care Med 1999; 160:216-20.

30. Van Berkel JJ, Dallinga JW, Möller GM, Godschalk RW, Moonen E, Wouters EF, et al. Development of accurate classification method based on the analysis of volatile organic compounds from human exhaled air. J Chromatogr B Analyt Technol Biomed Life Sci 2008; 861:101-7.

31. Kanoh S, Kobayashi H, Motoyoshi K. Exhaled ethane: an in vivo biomarker of lipid peroxidation in interstitial lung diseases. Chest 2005; 128:2387-92.

32. Kokoszka J, Nelson RL, Swedler WI, Skosey J, Abcarian H. Determination of inflammatory bowel disease activity by breath pentane analysis. Dis Colon Rectum 1993; 36:597-601.

33. Pelli MA, Trovarelli G, Capodicasa E, De Medio GE, Bassotti G. Breath alkanes determination in ulcerative colitis and Crohn's disease. Dis Colon Rectum 1999; 42:71-6.

34. Novak BJ, Blake DR, Meinardi S, Rowland FS, Pontello A, Cooper DM, et al. Exhaled methyl nitrate as a noninvasive marker of hyperglycemia in type 1 diabetes. Proc Natl Acad Sci U S A 2007; 104:15613-8.

35. Galassetti PR, Novak B, Nemet D, Rose-Gottron C, Cooper DM, Meinardi S, et al. Breath ethanol and acetone as indicators of serum glucose levels: an initial report. Diabetes Technol Ther 2005; 7:115-23. 
36. Graham JE. Bacterial volatiles and diagnosis of respiratory infections. Adv Appl Microbiol 2013; $82: 29-52$.

37. James GA, Swogger E, Wolcott R, Pulcini E, Secor P, Sestrich J, et al. Biofilms in chronic wounds. Wound Repair Regen 2008; 16:37-44.

38. Edmiston CE, McBain AJ, Roberts C, Leaper D. Clinical and microbiological aspects of biofilmassociated surgical site infections. Adv Exp Med Biol 2015; 830:47-67.

39. Cheadle WG. Risk factors for surgical site infection. Surg Infect (Larchmt) 2006; 7 Suppl 1:S7-11.

40. Watanabe A, Kohnoe S, Shimabukuro R, Yamanaka T, Iso Y, Baba H, et al. Risk factors associated with surgical site infection in upper and lower gastrointestinal surgery. Surg Today 2008; 38:404-12.

41. Chen CC, Collins SA, Rodgers AK, Paraiso MF, Walters MD, Barber MD. Perioperative complications in obese women vs normal-weight women who undergo vaginal surgery. Am J Obstet Gynecol 2007; 197:98.e1-8.

42. Sorensen LT, Karlsmark T, Gottrup F. Abstinence from smoking reduces incisional wound infection: a randomized controlled trial. Ann Surg 2003; 238:1-5.

43. Zerr KJ, Furnary AP, Grunkemeier GL, Bookin S, Kanhere V, Starr A. Glucose control lowers the risk of wound infection in diabetics after open heart operations. Ann Thorac Surg 1997; 63:356-61.

44. Mangram AJ, Horan TC, Pearson ML, Silver LC, Jarvis WR. Guideline for Prevention of Surgical Site Infection, 1999. Centers for Disease Control and Prevention (CDC) Hospital Infection Control Practices Advisory Committee. Am J Infect Control 1999; 27:97-132; quiz 3-4; discussion 96.

45. Cruse PJ, Foord R. The epidemiology of wound infection. A 10-year prospective study of 62,939 wounds. Surg Clin North Am 1980; 60:27-40.

46. Culver DH, Horan TC, Gaynes RP, Martone WJ, Jarvis WR, Emori TG, et al. Surgical wound infection rates by wound class, operative procedure, and patient risk index. National Nosocomial Infections Surveillance System. Am J Med 1991; 91:152S-7S.

47. Reichman DE, Greenberg JA. Reducing surgical site infections: a review. Rev Obstet Gynecol 2009; 2:212-21.

48. Kostakioti M, Hadjifrangiskou M, Hultgren SJ. Bacterial biofilms: development, dispersal, and therapeutic strategies in the dawn of the postantibiotic era. Cold Spring Harb Perspect Med 2013; 3:a010306.

49. Edwards R, Harding KG. Bacteria and wound healing. Curr Opin Infect Dis 2004; 17:91-6.

50. Wolcott RD, Ehrlich GD. Biofilms and chronic infections. JAMA 2008; 299:2682-4.

51. Gristina AG, Price JL, Hobgood CD, Webb LX, Costerton JW. Bacterial colonization of percutaneous sutures. Surgery 1985; 98:12-9.

52. Kathju S, Nistico L, Melton-Kreft R, Lasko LA, Stoodley P. Direct demonstration of bacterial biofilms on prosthetic mesh after ventral herniorrhaphy. Surg Infect (Larchmt) 2015; 16:45-53.

53. Høiby N, Ciofu O, Johansen HK, Song ZJ, Moser C, Jensen P, et al. The clinical impact of bacterial biofilms. Int J Oral Sci 2011; 3:55-65.

54. Akers KS, Mende K, Cheatle KA, Zera WC, Yu X, Beckius ML, et al. Biofilms and persistent wound infections in United States military trauma patients: a case-control analysis. BMC Infect Dis 2014; $14: 190$. 
55. Barnes S, Spencer M, Graham D, Johnson HB. Surgical wound irrigation: a call for evidence-based standardization of practice. Am J Infect Control 2014; 42:525-9.

56. Edmiston CE, Bruden B, Rucinski MC, Henen C, Graham MB, Lewis BL. Reducing the risk of surgical site infections: does chlorhexidine gluconate provide a risk reduction benefit? Am J Infect Control 2013; 41:S49-55.

57. Barber KE, Werth BJ, McRoberts JP, Rybak MJ. A novel approach utilizing biofilm time-kill curves to assess the bactericidal activity of ceftaroline combinations against biofilm-producing methicillinresistant Staphylococcus aureus. Antimicrob Agents Chemother 2014; 58:2989-92.

58. Romano A, Capozzi V, Spano G, Biasioli F. Proton transfer reaction-mass spectrometry: online and rapid determination of volatile organic compounds of microbial origin. Appl Microbiol Biotechnol 2015; 99:3787-95.

59. Tait E, Perry JD, Stanforth SP, Dean JR. Identification of volatile organic compounds produced by bacteria using HS-SPME-GC-MS. J Chromatogr Sci 2014; 52:363-73.

60. Zoller HF, Clark WM. THE PRODUCTION OF VOLATILE FATTY ACIDS BY BACTERIA OF THE DYSENTERY GROUP. J Gen Physiol 1921; 3:325-30.

61. Schulz S, Dickschat JS. Bacterial volatiles: the smell of small organisms. Nat Prod Rep 2007; 24:81442.

62. Korpi A, Järnberg J, Pasanen AL. Microbial volatile organic compounds. Crit Rev Toxicol 2009; 39:139-93.

63. Heddergott C, Calvo AM, Latgé JP. The volatome of Aspergillus fumigatus. Eukaryot Cell 2014; 13:1014-25.

64. Dormont L, Bessière JM, Cohuet A. Human skin volatiles: a review. J Chem Ecol 2013; 39:569-78.

65. Jiang R, Cudjoe E, Bojko B, Abaffy T, Pawliszyn J. A non-invasive method for in vivo skin volatile compounds sampling. Anal Chim Acta 2013; 804:111-9.

66. Mochalski P, King J, Unterkofler K, Hinterhuber H, Amann A. Emission rates of selected volatile organic compounds from skin of healthy volunteers. J Chromatogr B Analyt Technol Biomed Life Sci 2014; 959:62-70.

67. Gallagher M, Wysocki CJ, Leyden JJ, Spielman AI, Sun X, Preti G. Analyses of volatile organic compounds from human skin. Br J Dermatol 2008; 159:780-91.

68. Martínez-Lozano P, de la Mora JF. On-line detection of human skin vapors. J Am Soc Mass Spectrom 2009; 20:1060-3.

69. Beale DJ, Jones OA, Karpe AV, Dayalan S, Oh DY, Kouremenos KA, et al. A Review of Analytical Techniques and Their Application in Disease Diagnosis in Breathomics and Salivaomics Research. Int J Mol Sci 2016; 18.

70. Sweetlove LJ, Last RL, Fernie AR. Predictive metabolic engineering: a goal for systems biology. Plant Physiol 2003; 132:420-5.

71. Jones OA, Cheung VL. An introduction to metabolomics and its potential application in veterinary science. Comp Med 2007; 57:436-42.

72. Hall R, Beale M, Fiehn O, Hardy N, Sumner L, Bino R. Plant metabolomics: the missing link in functional genomics strategies. Plant Cell 2002; 14:1437-40. 
73. Eiceman GA, Bergloff JF, Rodriguez JE, Munro W, Karpas Z. Atmospheric pressure chemical ionization of fluorinated phenols in atmospheric pressure chemical ionization mass spectrometry, tandem mass spectrometry, and ion mobility spectrometry. J Am Soc Mass Spectrom 1999; 10:115765.

74. D'Agostino PA, Chenier CL. Desorption electrospray ionization mass spectrometric analysis of organophosphorus chemical warfare agents using ion mobility and tandem mass spectrometry. Rapid Commun Mass Spectrom 2010; 24:1617-24.

75. Baumbach JI, Eiceman GA. Ion mobility spectrometry: arriving on site and moving beyond a low profile. Appl Spectrosc 1999; 53:338A-55A.

76. Maddula S, Blank LM, Schmid A, Baumbach JI. Detection of volatile metabolites of Escherichia coli by multi capillary column coupled ion mobility spectrometry. Anal Bioanal Chem 2009; 394:791-800.

77. Baumbach JI. Process analysis using ion mobility spectrometry. Anal Bioanal Chem 2006; 384:105970.

78. Dragonieri S, Schot R, Mertens BJ, Le Cessie S, Gauw SA, Spanevello A, et al. An electronic nose in the discrimination of patients with asthma and controls. J Allergy Clin Immunol 2007; 120:856-62.

79. Verhulst NO, Beijleveld H, Knols BG, Takken W, Schraa G, Bouwmeester HJ, et al. Cultured skin microbiota attracts malaria mosquitoes. Malar J 2009; 8:302.

80. Saranya R, Aarthi R, Sankaran K. Simple and specific colorimetric detection of Staphylococcus using its volatile 2-[3-acetoxy-4,4,14-trimethylandrost-8-en-17-yl] propanoic acid in the liquid phase and head space of cultures. Appl Microbiol Biotechnol 2015; 99:4423-33.

81. Bianchi F, Careri M, Mangia A, Mattarozzi M, Musci M, Concina I, et al. Differentiation of the volatile profile of microbiologically contaminated canned tomatoes by dynamic headspace extraction followed by gas chromatography-mass spectrometry analysis. Talanta 2009; 77:962-70.

82. Zscheppank C, Wiegand HL, Lenzen C, Wingender J, Telgheder U. Investigation of volatile metabolites during growth of Escherichia coli and Pseudomonas aeruginosa by needle trap-GC-MS. Anal Bioanal Chem 2014; 406:6617-28.

83. Boots AW, Smolinska A, van Berkel JJ, Fijten RR, Stobberingh EE, Boumans ML, et al. Identification of microorganisms based on headspace analysis of volatile organic compounds by gas chromatography-mass spectrometry. J Breath Res 2014; 8:027106.

84. Scott-Thomas AJ, Syhre M, Pattemore PK, Epton M, Laing R, Pearson J, et al. 2-Aminoacetophenone as a potential breath biomarker for Pseudomonas aeruginosa in the cystic fibrosis lung. BMC Pulm Med 2010; 10:56.

85. Umber BJ, Shin HW, Meinardi S, Leu SY, Zaldivar F, Cooper DM, et al. Gas signatures from Escherichia coli and Escherichia coli-inoculated human whole blood. Clin Transl Med 2013; 2:13.

86. Yu K, Hamilton-Kemp TR, Archbold DD, Collins RW, Newman MC. Volatile compounds from Escherichia coli O157:H7 and their absorption by strawberry fruit. J Agric Food Chem 2000; 48:413-7.

87. Filipiak W, Sponring A, Baur MM, Filipiak A, Ager C, Wiesenhofer H, et al. Molecular analysis of volatile metabolites released specifically by Staphylococcus aureus and Pseudomonas aeruginosa. BMC Microbiol 2012; 12:113. 
88. Bean HD, Dimandja JM, Hill JE. Bacterial volatile discovery using solid phase microextraction and comprehensive two-dimensional gas chromatography-time-of-flight mass spectrometry. J Chromatogr B Analyt Technol Biomed Life Sci 2012; 901:41-6.

89. Schöller C, Molin S, Wilkins K. Volatile metabolites from some gram-negative bacteria. Chemosphere 1997; 35:1487-95.

90. Zhu J, Bean HD, Kuo YM, Hill JE. Fast detection of volatile organic compounds from bacterial cultures by secondary electrospray ionization-mass spectrometry. J Clin Microbiol 2010; 48:4426-31.

91. Kunze N, Göpel J, Kuhns M, Jünger M, Quintel M, Perl T. Detection and validation of volatile metabolic patterns over different strains of two human pathogenic bacteria during their growth in a complex medium using multi-capillary column-ion mobility spectrometry (MCC-IMS). Appl Microbiol Biotechnol 2013; 97:3665-76.

92. Dolch ME, Hornuss C, Klocke C, Praun S, Villinger J, Denzer W, et al. Volatile organic compound analysis by ion molecule reaction mass spectrometry for Gram-positive bacteria differentiation. Eur $\mathbf{J}$ Clin Microbiol Infect Dis 2012; 31:3007-13.

93. Neerincx AH, Geurts BP, Habets MF, Booij JA, van Loon J, Jansen JJ, et al. Identification of Pseudomonas aeruginosa and Aspergillus fumigatus mono- and co-cultures based on volatile biomarker combinations. J Breath Res 2016; 10:016002.

94. Preti G, Thaler E, Hanson CW, Troy M, Eades J, Gelperin A. Volatile compounds characteristic of sinus-related bacteria and infected sinus mucus: analysis by solid-phase microextraction and gas chromatography-mass spectrometry. J Chromatogr B Analyt Technol Biomed Life Sci 2009; 877:20118 .

95. Elgaali H, Hamilton-Kemp TR, Newman MC, Collins RW, Yu K, Archbold DD. Comparison of longchain alcohols and other volatile compounds emitted from food-borne and related Gram positive and Gram negative bacteria. J Basic Microbiol 2002; 42:373-80.

96. Shestivska V, Nemec A, Dřevínek P, Sovová K, Dryahina K, Spaněl P. Quantification of methyl thiocyanate in the headspace of Pseudomonas aeruginosa cultures and in the breath of cystic fibrosis patients by selected ion flow tube mass spectrometry. Rapid Commun Mass Spectrom 2011; 25:245967.

97. Shestivska V, Spaněl P, Dryahina K, Sovová K, Smith D, Musílek M, et al. Variability in the concentrations of volatile metabolites emitted by genotypically different strains of Pseudomonas aeruginosa. J Appl Microbiol 2012; 113:701-13.

98. Guamán AV, Carreras A, Calvo D, Agudo I, Navajas D, Pardo A, et al. Rapid detection of sepsis in rats through volatile organic compounds in breath. J Chromatogr B Analyt Technol Biomed Life Sci 2012; 881-882:76-82.

99. Lechner M, Fille M, Hausdorfer J, Dierich MP, Rieder J. Diagnosis of bacteria in vitro by mass spectrometric fingerprinting:a pilot study. Curr Microbiol 2005; 51:267-9.

100. O'Hara M, Mayhew CA. A preliminary comparison of volatile organic compounds in the headspace of cultures of Staphylococcus aureus grown in nutrient, dextrose and brain heart bovine broths measured using a proton transfer reaction mass spectrometer. J Breath Res 2009; 3:027001. 
101. Luchner M, Gutmann R, Bayer K, Dunk1 J, Hansel A, Herbig J, et al. Implementation of proton transfer reaction-mass spectrometry (PTR-MS) for advanced bioprocess monitoring. Biotechnol Bioeng 2012; 109:3059-69.

102. Asl-Hariri S, Gómez-Ríos GA, Gionfriddo E, Dawes P, Pawliszyn J. Development of needle trap technology for on-site determinations: active and passive sampling. Anal Chem 2014; 86:5889-97.

103. Zhu J, Hill JE. Detection of Escherichia coli via VOC profiling using secondary electrospray ionization-mass spectrometry (SESI-MS). Food Microbiol 2013; 34:412-7.

104. Carroll W, Lenney W, Wang T, Spanel P, Alcock A, Smith D. Detection of volatile compounds emitted by Pseudomonas aeruginosa using selected ion flow tube mass spectrometry. Pediatr Pulmonol 2005; 39:452-6.

105. Gilchrist FJ, Bright-Thomas RJ, Jones AM, Smith D, Spaněl P, Webb AK, et al. Hydrogen cyanide concentrations in the breath of adult cystic fibrosis patients with and without Pseudomonas aeruginosa infection. J Breath Res 2013; 7:026010.

106. Allardyce RA, Hill AL, Murdoch DR. The rapid evaluation of bacterial growth and antibiotic susceptibility in blood cultures by selected ion flow tube mass spectrometry. Diagn Microbiol Infect Dis 2006; 55:255-61.

107. Storer MK, Hibbard-Melles K, Davis B, Scotter J. Detection of volatile compounds produced by microbial growth in urine by selected ion flow tube mass spectrometry (SIFT-MS). J Microbiol Methods 2011; 87:111-3.

108. Sovová K, Čepl J, Markoš A, Španěl P. Real time monitoring of population dynamics in concurrent bacterial growth using SIFT-MS quantification of volatile metabolites. Analyst 2013; 138:4795-801.

109. Chippendale TW, Španěl P, Smith D. Time-resolved selected ion flow tube mass spectrometric quantification of the volatile compounds generated by E. coli JM109 cultured in two different media. Rapid Commun Mass Spectrom 2011; 25:2163-72.

110. Bunge M, Araghipour N, Mikoviny T, Dunkl J, Schnitzhofer R, Hansel A, et al. On-line monitoring of microbial volatile metabolites by proton transfer reaction-mass spectrometry. Appl Environ Microbiol 2008; 74:2179-86.

111. Shafiek H, Fiorentino F, Merino JL, López C, Oliver A, Segura J, et al. Using the Electronic Nose to Identify Airway Infection during COPD Exacerbations. PLoS One 2015; 10:e0135199.

112. Dutta R, Hines EL, Gardner JW, Boilot P. Bacteria classification using Cyranose 320 electronic nose. Biomed Eng Online 2002; 1:4.

113. Abdallah SA, Al-Shatti LA, Alhajraf AF, Al-Hammad N, Al-Awadi B. The detection of foodborne bacteria on beef: the application of the electronic nose. Springerplus 2013; 2:687.

114. Shores JT, Gabriel A, Gupta S. Skin substitutes and alternatives: a review. Adv Skin Wound Care 2007; 20:493-508; quiz 9-10.

115. Lee SH, Jeong SK, Ahn SK. An update of the defensive barrier function of skin. Yonsei Med J 2006; 47:293-306.

116. Noël F, Piérard-Franchimont C, Piérard GE, Quatresooz P. Sweaty skin, background and assessments. Int J Dermatol 2012; 51:647-55. 
117. Taylor D, Daulby A, Grimshaw S, James G, Mercer J, Vaziri S. Characterization of the microflora of the human axilla. Int J Cosmet Sci 2003; 25:137-45.

118. Natsch A, Gfeller H, Gygax P, Schmid J. Isolation of a bacterial enzyme releasing axillary malodor and its use as a screening target for novel deodorant formulations. Int J Cosmet Sci 2005; 27:115-22.

119. Natsch A, Derrer S, Flachsmann F, Schmid J. A broad diversity of volatile carboxylic acids, released by a bacterial aminoacylase from axilla secretions, as candidate molecules for the determination of human-body odor type. Chem Biodivers 2006; 3:1-20.

120. Amann A, Costello BeL, Miekisch W, Schubert J, Buszewski B, Pleil J, et al. The human volatilome: volatile organic compounds (VOCs) in exhaled breath, skin emanations, urine, feces and saliva. J Breath Res 2014; 8:034001.

121. Mochalski P, Unterkofler K, Hinterhuber H, Amann A. Monitoring of selected skin-borne volatile markers of entrapped humans by selective reagent ionization time of flight mass spectrometry in NO+ mode. Anal Chem 2014; 86:3915-23.

122. Ruzsanyi V, Mochalski P, Schmid A, Wiesenhofer H, Klieber M, Hinterhuber H, et al. Ion mobility spectrometry for detection of skin volatiles. J Chromatogr B Analyt Technol Biomed Life Sci 2012; 911:84-92.

123. Havlicek J, Lenochova P. The effect of meat consumption on body odor attractiveness. Chem Senses 2006; 31:747-52.

124. Bernier UR, Kline DL, Barnard DR, Schreck CE, Yost RA. Analysis of human skin emanations by gas chromatography/mass spectrometry. 2. Identification of volatile compounds that are candidate attractants for the yellow fever mosquito (Aedes aegypti). Anal Chem 2000; 72:747-56.

125. Logan JG, Birkett MA, Clark SJ, Powers S, Seal NJ, Wadhams LJ, et al. Identification of humanderived volatile chemicals that interfere with attraction of Aedes aegypti mosquitoes. J Chem Ecol 2008; 34:308-22.

126. Harraca V, Ryne C, Birgersson G, Ignell R. Smelling your way to food: can bed bugs use our odour? J Exp Biol 2012; 215:623-9.

127. Zeng XN, Leyden JJ, Spielman AI, Preti G. Analysis of characteristic human female axillary odors: Qualitative comparison to males. J Chem Ecol 1996; 22:237-57.

128. Curran AM, Rabin SI, Prada PA, Furton KG. Comparison of the volatile organic compounds present in human odor using SPME-GC/MS. J Chem Ecol 2005; 31:1607-19.

129. Zhang ZM, Cai JJ, Ruan GH, Li GK. The study of fingerprint characteristics of the emanations from human arm skin using the original sampling system by SPME-GC/MS. J Chromatogr B Analyt Technol Biomed Life Sci 2005; 822:244-52.

130. Dormont L, Bessière JM, McKey D, Cohuet A. New methods for field collection of human skin volatiles and perspectives for their application in the chemical ecology of human-pathogen-vector interactions. J Exp Biol 2013; 216:2783-8.

131. Penn DJ, Oberzaucher E, Grammer K, Fischer G, Soini HA, Wiesler D, et al. Individual and gender fingerprints in human body odour. J R Soc Interface 2007; 4:331-40.

132. Ara K, Hama M, Akiba S, Koike K, Okisaka K, Hagura T, et al. Foot odor due to microbial metabolism and its control. Can J Microbiol 2006; 52:357-64. 
133. Caroprese A, Gabbanini S, Beltramini C, Lucchi E, Valgimigli L. HS-SPME-GC-MS analysis of body odor to test the efficacy of foot deodorant formulations. Skin Res Technol 2009; 15:503-10.

134. Haze S, Gozu Y, Nakamura S, Kohno Y, Sawano K, Ohta H, et al. 2-Nonenal newly found in human body odor tends to increase with aging. J Invest Dermatol 2001; 116:520-4.

135. D'Amico A, Bono R, Pennazza G, Santonico M, Mantini G, Bernabei M, et al. Identification of melanoma with a gas sensor array. Skin Res Technol 2008; 14:226-36.

136. Kwak J, Gallagher M, Ozdener MH, Wysocki CJ, Goldsmith BR, Isamah A, et al. Volatile biomarkers from human melanoma cells. J Chromatogr B Analyt Technol Biomed Life Sci 2013; 931:90-6.

137. Abaffy T, Duncan R, Riemer DD, Tietje O, Elgart G, Milikowski C, et al. Differential volatile signatures from skin, naevi and melanoma: a novel approach to detect a pathological process. PLoS One 2010; 5:e13813.

138. Abaffy T, Möller M, Riemer DD, Milikowski C, Defazio RA. A case report - Volatile metabolomic signature of malignant melanoma using matching skin as a control. J Cancer Sci Ther 2011; 3:140-4.

139. Abaffy T, Möller MG, Riemer DD, Milikowski C, DeFazio RA. Comparative analysis of volatile metabolomics signals from melanoma and benign skin: a pilot study. Metabolomics 2013; 9:998-1008.

140. Voss A, Witt K, Fischer C, Reulecke S, Poitz W, Kechagias V, et al. Smelling heart failure from human skin odor with an electronic nose. Conf Proc IEEE Eng Med Biol Soc 2012; 2012:4034-7.

141. Turner C, Parekh B, Walton C, Spanel P, Smith D, Evans M. An exploratory comparative study of volatile compounds in exhaled breath and emitted by skin using selected ion flow tube mass spectrometry. Rapid Commun Mass Spectrom 2008; 22:526-32.

142. Parry AD, Chadwick PR, Simon D, Oppenheim B, McCollum CN. Leg ulcer odour detection identifies beta-haemolytic streptococcal infection. J Wound Care 1995; 4:404-6.

143. Thomas AN, Riazanskaia S, Cheung W, Xu Y, Goodacre R, Thomas CL, et al. Novel noninvasive identification of biomarkers by analytical profiling of chronic wounds using volatile organic compounds. Wound Repair Regen 2010; 18:391-400.

144. Dini F, Capuano R, Strand T, Ek AC, Lindgren M, Paolesse R, et al. Volatile emissions from compressed tissue. PLoS One 2013; 8:e69271.

145. Silkoff PE, Carlson M, Bourke T, Katial R, Ogren E, Szefler SJ. The Aerocrine exhaled nitric oxide monitoring system NIOX is cleared by the US Food and Drug Administration for monitoring therapy in asthma. J Allergy Clin Immunol 2004; 114:1241-56.

146. Graham DY, Klein PD, Evans DJ, Evans DG, Alpert LC, Opekun AR, et al. Campylobacter pylori detected noninvasively by the 13C-urea breath test. Lancet 1987; 1:1174-7.

147. Phillips M, Boehmer JP, Cataneo RN, Cheema T, Eisen HJ, Fallon JT, et al. Heart allograft rejection: detection with breath alkanes in low levels (the HARDBALL study). J Heart Lung Transplant 2004; 23:701-8.

148. Wilson AD, Baietto M. Advances in electronic-nose technologies developed for biomedical applications. Sensors (Basel) 2011; 11:1105-76.

149. Modak AS. Regulatory issues on breath tests and updates of recent advances on [13C]-breath tests. J Breath Res 2013; 7:037103. 
150. Neerincx AH, Geurts BP, van Loon J, Tiemes V, Jansen JJ, Harren FJ, et al. Detection of Staphylococcus aureus in cystic fibrosis patients using breath VOC profiles. J Breath Res 2016; 10:046014.

151. Dryahina K, Sovová K, Nemec A, Španěl P. Differentiation of pulmonary bacterial pathogens in cystic fibrosis by volatile metabolites emitted by their in vitro cultures: Pseudomonas aeruginosa, Staphylococcus aureus, Stenotrophomonas maltophilia and the Burkholderia cepacia complex. J Breath Res 2016; 10:037102.

152. Shirasu M, Touhara K. The scent of disease: volatile organic compounds of the human body related to disease and disorder. J Biochem 2011; 150:257-66.

153. Abd El Qader A, Lieberman D, Shemer Avni Y, Svobodin N, Lazarovitch T, Sagi O, et al. Volatile organic compounds generated by cultures of bacteria and viruses associated with respiratory infections. Biomed Chromatogr 2015; 29:1783-90.

154. Sebastian A, Iqbal SA, Colthurst J, Volk SW, Bayat A. Electrical stimulation enhances epidermal proliferation in human cutaneous wounds by modulating p53-SIVA1 interaction. J Invest Dermatol 2015; 135:1166-74. 
Table 1. Common volatile organic compounds produced by bacteria associated with cutaneous wound and surgical site infections

\begin{tabular}{|c|c|}
\hline Bacteria & VOC \\
\hline P. aeruginosa & 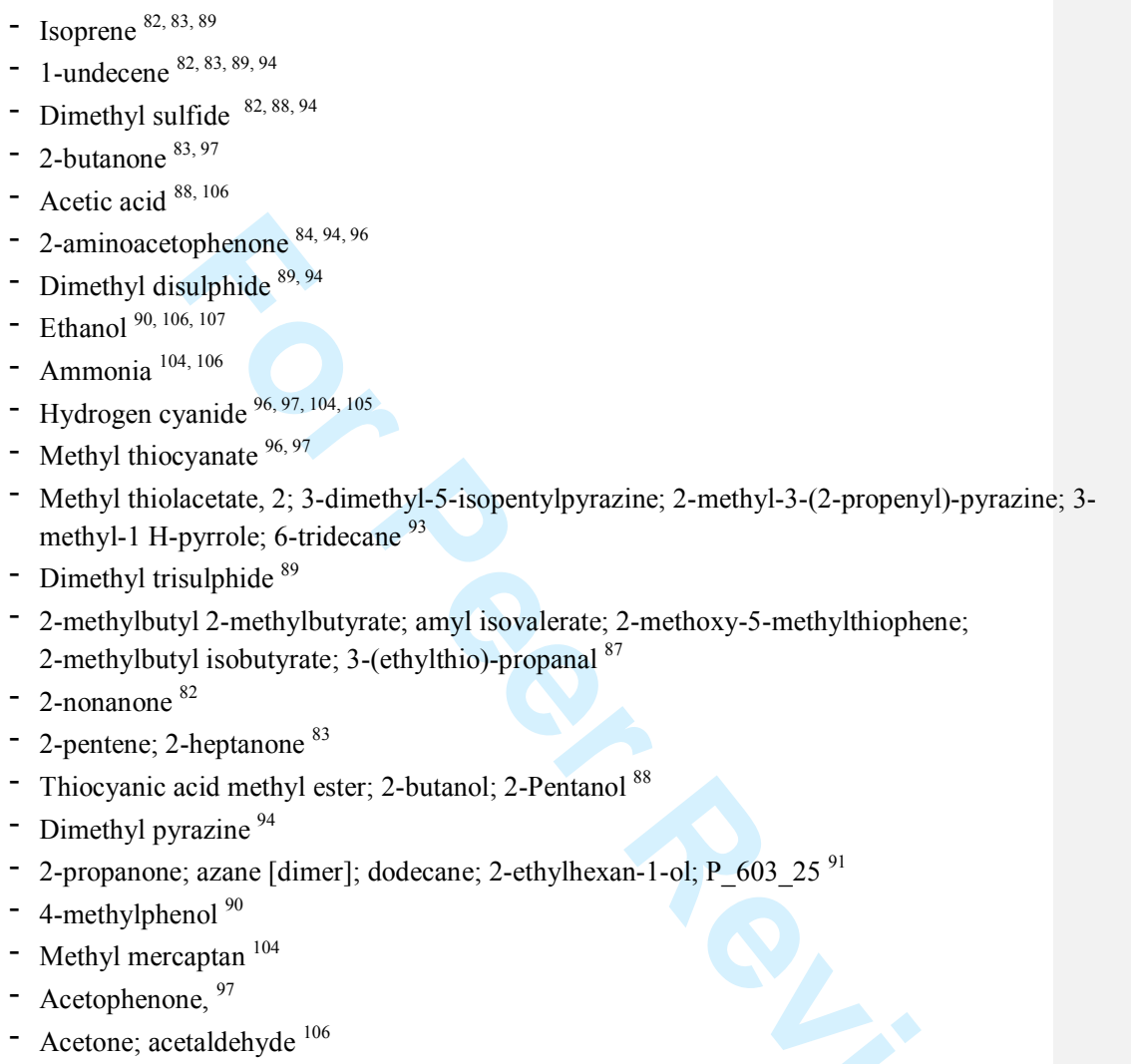 \\
\hline E. coli & 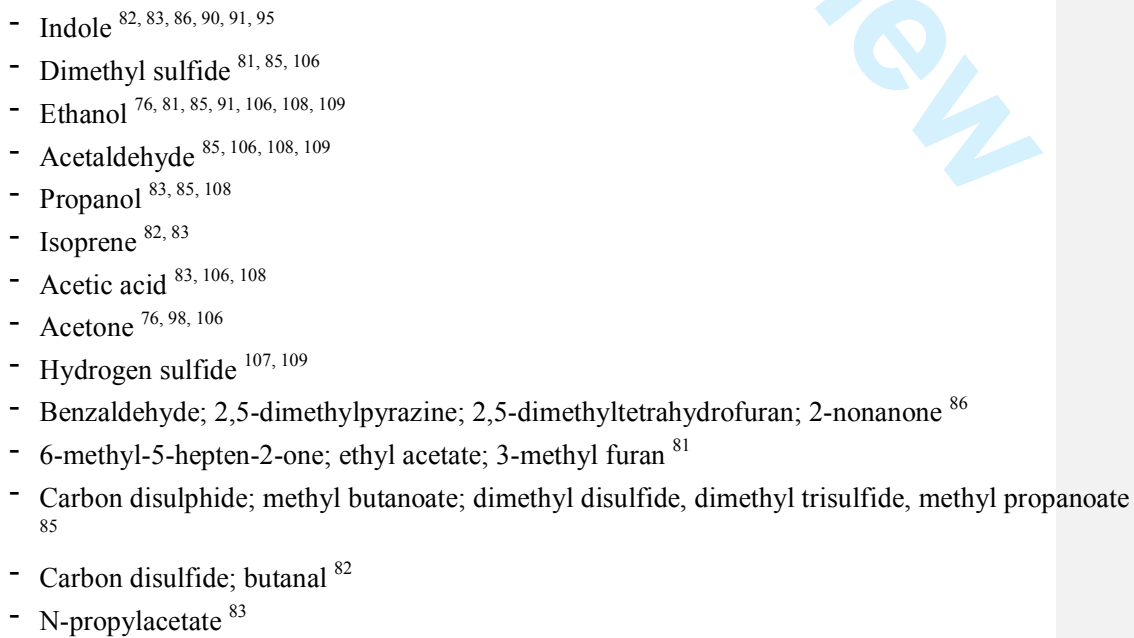 \\
\hline
\end{tabular}


- 2-methylbutanol; 3-methylbutanol ${ }^{95}$

- Heptan-2-one; nonan-2-one ${ }^{76}$

- Methyl cyclohexane; carbon dioxide; pentafluoropropionamide; Dimethylether ${ }^{98}$

- Decan-1-ol; Octan-1-ol ${ }^{91}$

- Formaldehyde; methyl mercaptan ${ }^{107}$

- ammonia $^{109}$

S. aureus

- Ethanol ${ }^{87,106}$

- Acetic acid ${ }^{87,90}$

- Acetaldehyde ${ }^{87,106}$

- Acetone $83,90,106$

- Dimethyl disulfide ${ }^{83,95}$

- Ammonia 106,107

- 3-methylbutanal; 2-methylpropanal ${ }^{87}$

- 1,1,2,2-tetrachloroethane; dimethyl trisulfide ${ }^{83}$

- Isovaleric acid; 2-methylbutyric acid; isobutyric acid; 1-hydroxy-2-propanone; 3-hydroxy-2-butanone ${ }^{94}$

- 2-tridecenone ${ }^{95}$

- Butanol ${ }^{90}$

- Dimethyl sulfide ${ }^{106}$

MRSA - 2-heptanone; 1,4-dichlorobenzene ${ }^{83}$

S. pyogenes

E. faecalis - Ammonia ${ }^{107}$

S. epidermidis - 3-methyl-1-butanol; 2-methylbutanal; 3-methylbutanoic acid ; 2-methylbutanoic acid ${ }^{80}$

- Ammonia; acetone ${ }^{107}$

VOC - volatile organic compound; P. aeruginosa - Pseudomonas aeruginosa; E. coli Escherichia coli; S. aureus - Staphylococcus aureus; MRSA - methicillin resistant staphylococcus aureus; S. pyogenes - Streptococcus pyogenes; E. faecalis - Enterococcus faecalis; S. epidermidis - Staphylococcus epidermidis. 
Table 2. Unique and shared VOCs between bacteria

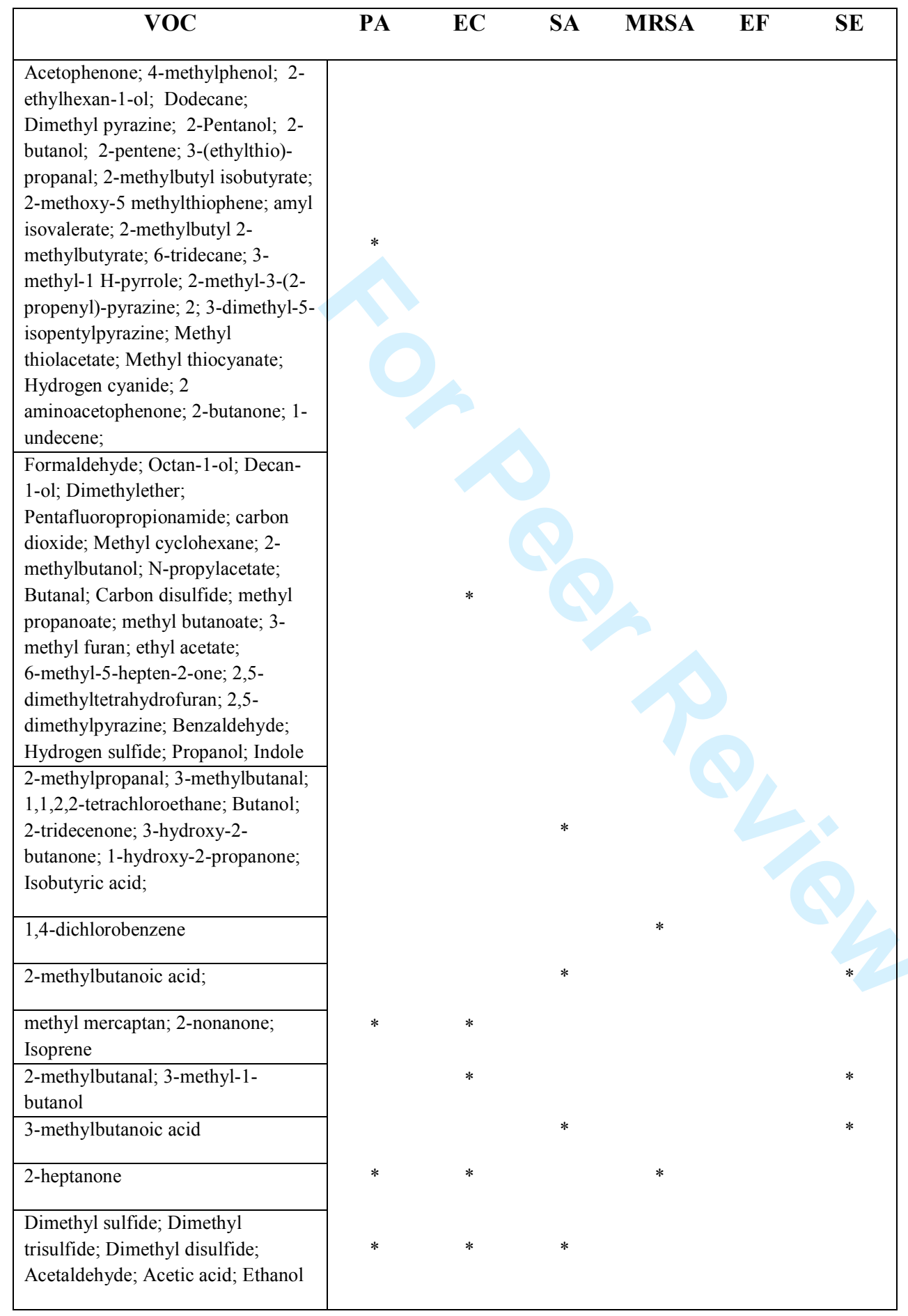


SA - Staphylococcus aureus; MRSA - methicillin resistant staphylococcus aureus; SP Streptococcus pyogenes; EF - Enterococcus faecalis; SE - Staphylococcus epidermidis. 


\section{Figure Legend}

Figure 1. Volatile organic compound sampling techniques. Spider diagram outlining the common volatile organic compound sampling techniques including their advantages and limitations. VOC - volatile organic compound; GC- gas chromatography; SPME - solid phase micro-extraction; $T D$ - thermal desorption.

Figure 2. Volatile organic compound analytical techniques. Spider diagram outlining the common volatile organic compound analytical techniques including their advantages and limitations. ToF - time of flight; GC-gas chromatography; $M S$ - mass spectrometry; VOC volatile organic compound; SIFT-MS - Selected ion flow tube-mass spectrometry; IMR-MS Ion molecule reaction mass spectrometry; SESI-MS - Secondary electrospray ionisation-mass spectrometry; PTR-MS - Proton transfer reaction-mass spectrometry; IMS - ion mobility spectrometry; MCC - multi capillary columns.

Figure 3. Common volatile organic compounds produced and emitted from skin. Volatile organic compounds in skin are produced by interactions between the secretions from sebaceous, apocrine and eccrine glands and bacteria. Volatile organic compounds detected can be affected by environmental factors. VOC - volatile organic compound.

Figure 4. Volatile organic compounds emitted bodily sites. Volatile organic compounds emitted from the human body vary dependent on site. 


\title{
Volatile organic compound detection as a potential means of
}

\section{diagnosing cutaneous wound infections}

\author{
Mohammed Ashrafi MB $\mathrm{ChB}^{1,3,4}$, Matt Bates $\mathrm{MChem}^{2}$, Mohamed Baguneid MD ${ }^{3}$, Teresa Alonso- \\ Rasgado $\mathrm{PhD}^{4}$, Riina Rautemaa-Richardson $\mathrm{MD} \mathrm{PhD}^{5}$, Ardeshir Bayat MB BS $\mathrm{PhD}^{* 1,4}$ \\ ${ }^{1}$ Plastic and Reconstructive Surgery Research, Centre for Dermatological Research, Institute of \\ Inflammation and Repair, University of Manchester, UK \\ ${ }^{2}$ MCBA Consulting, Cardiff, UK.
}

${ }^{3}$ University Hospital South Manchester NHS Foundation Trust, Wythenshawe Hospital, Manchester, UK

${ }^{4}$ Bioengineering Group, School of Materials, University of Manchester, UK

${ }^{5}$ Manchester Academic Health Science Centre, Institute of Inflammation and Repair, University of Manchester; and University Hospital of South Manchester, Wythenshawe Hospital, Manchester, UK

\author{
*Corresponding author at: Dr Ardeshir Bayat, Associate Professor, Institute of Inflammation \& \\ Repair, Stopford Building, Manchester M13 9PT, UK. Tel: +44 1613060607. \\ E-mail address: ardeshir.bayat@manchester.ac.uk
}

Running title: VOC detection and wound infection diagnosis

Keywords: Cutaneous wounds; volatile organic compound; skin; infection 


\section{Abstract}

Chronic cutaneous wound infections and surgical site infections (SSIs) present a huge burden on the healthcare system and can lead to increased morbidity and mortality. Current diagnostic methods of identifying and confirming infection involve culture-based and molecular methods. Both techniques are time consuming and delays commonly lead to untargeted empirical treatment. An ideal diagnostic method would be non-invasive and highly sensitive and detect pathogenic organisms with a high degree of accuracy in order to allow targeted treatment. Volatile organic compounds (VOCs) are a diverse group of carbon-based molecules produced and released by humans and microorganisms. VOC detection has the potential in aiding cutaneous wound infection diagnostics using non-invasive and timeefficient methods. This review provides a comprehensive update on VOCs produced and emitted by bacteria commonly associated with chronic wounds and SSIs. VOC sampling has the advantage of being painless, time-efficient, non-invasive and reproducible. VOCs emitted by these organisms are diverse. In vitro studies have identified potential signature volatile profiles, which can be used in detecting these microorganisms. Combining these profiles with volatile profiles emitted from acute, chronic and surgical wounds in vivo could potentially allow identification of bacterial-specific VOCs. VOC detection has the potential for a relatively inexpensive, portable, non-invasive and reliable clinical diagnostic tool, which could be used in detecting cutaneous wound infections and guiding their optimal management. 


\section{Introduction}

Chronic cutaneous wounds occur as a result of deficiencies in wound healing processes ${ }^{1,2}$. Chronic wounds have a major impact on patient's quality of life and present a huge burden on the healthcare system ${ }^{3,4}$. Persistent cutaneous wound infection is a major contributor to delayed wound healing ${ }^{5,6}$. Cutaneous infection following post-surgical intervention is also of clinical concern. Surgical site infections (SSIs) are common complications after surgery and can lead to increased morbidity and mortality ${ }^{7,8}$. Common bacterial pathogens associated with chronic as well as superficial and deep SSIs include Staphylococcus aureus, Staphylococcus epidermidis, Escherichia coli, Pseudomonas aeruginosa, Streptococcus pyogenes and Enterococcus faecalis ${ }^{9-12}$. Current diagnostic methods of identifying and confirming cutaneous infections involve culture-based and molecular methods. Both techniques are time consuming, and culture-based methods have limited sensitivity and are susceptible to over-estimation of skin commensals leading to incorrect causative bacterial identification ${ }^{13-15}$. Delays in diagnostics often result in the use of untargeted empirical treatment with a risk for sub-optimal choice of antibiotics, the development of antibiotic resistance and increase in mortality ${ }^{16}$. An ideal diagnostic method would be non-invasive and highly sensitive and detect pathogenic organisms with a high degree of accuracy in order to allow targeted treatment.

Volatile organic compounds (VOCs) are a diverse group of carbon based molecules, including alcohols, isocyanates, ketones, aldehydes, hydrocarbons and sulphides, which are volatile at ambient temperatures ${ }^{17,18}$. VOC sampling has the advantage of being painless, non-invasive and reproducible. A compendium of VOCs emanating from the human body has been compiled with 1840 VOCs assigned from breath (872), saliva (359), blood (154), 
milk (256), skin secretions (532) urine (279), and faeces (381) ${ }^{19}$. There is increasing evidence that VOCs or combinations of VOCs are unique to various disease states and their early detection could represent a useful means of diagnosis. VOCs have been identified as potential biomarkers in malignancies of the lung ${ }^{20}$, stomach ${ }^{21}$, head and neck ${ }^{22}$, breast ${ }^{23}$, liver ${ }^{24,25}$ colon and prostate ${ }^{26}$. They have also been detected as markers of asthma ${ }^{27-29}$, chronic obstructive pulmonary disease ${ }^{30,31}$, inflammatory bowel disease ${ }^{32,33}$ and diabetes ${ }^{34}$, 35. Microorganisms produce and release VOCs and currently volatile detection via breath testing has been at the forefront in the potential of this technology to diagnose infection ${ }^{36}$. The ability to identify VOCs in cutaneous wound infections could lead to a non-invasive and time efficient method of diagnosis.

The aim of this review is to provide a detailed update on VOCs produced and emitted by bacterial species commonly associated with cutaneous wound infections. It then describes the volatile profile of skin in health and disease. Finally, the role of volatile detection from cutaneous wounds is discussed. An extensive literature search was conducted on PubMed for relevant articles published from 1960 onwards. MeSH terms used included a variety of combinations including: SSI, surgical wound infection, VOCs, biofilm, staphylococcus, Escherichia coli, streptococcus, enterococcus, Pseudomonas aeruginosa, gram positive bacteria, gram negative bacteria, wound infection, post-operative wound infection, wound healing and skin. 


\section{Chronic wounds and SSIs}

Chronic wounds represent a major burden on patients with the National Health Service expenditure in managing these wounds in excess of $£ 1$ billion annually ${ }^{3}$. Biofilms are present in more than half of chronic wounds and present a major obstacle in healing ${ }^{37}$. Over 50 million in-patient surgical procedures are performed in the USA annually with approximately $1-5 \%$ developing SSIs with a high associated mortality ${ }^{38,39}$. SSIs pose a significant burden on the healthcare system leading to increase postoperative in-patient stay, increased expenses and readmissions. The preliminary management of SSIs involves preventative measures which include but are not limited to peri-operative antibiotics and meticulous skin preparation prior to the procedure. However, despite these measures SSIs represent the most common hospital acquired infections in surgical patients ${ }^{40}$. Risk factors associated with SSIs include patient and operative factors. Patient factors include diabetes, obesity, smoking and preoperative active infection ${ }^{41-43}$. Operative factors include wound characteristics which can be classified into four categories, namely, clean, clean-contaminated, contaminated and dirtyinfected ${ }^{44}$. An escalating risk of developing SSIs is linked to the level of wound characterisation ranging from $1.3 \%$ for clean wounds to $40 \%$ for dirty-infected wounds 45,46 . Other operative factors include preoperative showering and hair removal, hand-washing and surgical attire, and intra-operative skin preparation ${ }^{47}$.

Planktonic bacteria undergo a four phase cycle of growth consisting of a lag phase, log phase, stationary phase and death phase. Biofilms are physiologically distinct from their planktonic counterparts and undergo a different developmental cycle, which involves initial attachment to the surface, irreversible attachment, maturation and dispersion ${ }^{48}$. Biofilms are more prevalent than expected in surgical wounds with up to $80 \%$ of SSIs involving the presence of 
biofilm ${ }^{49}$. They are difficult to diagnose with culture methods proving obsolete in their detection ${ }^{50}$. Biofilms have been found on closure materials of healed surgical wounds ${ }^{51}$ and on the surface of implanted surgical devices ${ }^{52}$. Biofilms are significantly more difficult to eradicate leading to a chronic inflammatory state which further negatively impacts wound healing ${ }^{53}$ and persistence of infection ${ }^{54}$. Management of SSI associated biofilms requires invasive management involving surgical debridement of devitalised tissue, removal of infected devices and parenteral broad-spectrum antimicrobials ${ }^{55-57}$. This further highlights the need for rapid and accurate diagnostic tools in order to avoid a delay in optimum management.

SSIs are classified into three categories: superficial incisional where the infection occurs around the area of the skin where the incision was made; deep incisional where the infection occurs deep to the incision effecting the underlying fascia and muscle; and organ/space where the infection effects the organs or body cavities ${ }^{44}$. We propose the potential use of volatile detection as a means of diagnosing SSIs would be limited to superficial SSI and potentially deep SSI as these would allow the non-invasive capture of VOCs. The most typical causative micro-organisms of superficial and deep SSIs are pathogens native to the patient's skin which include staphylococci, streptococci, enterococci and gram negative bacilli ${ }^{47}$. 


\section{Microorganisms and VOCs}

A portion of normal microbial metabolites produced are VOCs ${ }^{58}$. They are thought to evolve as products or by-products of metabolic pathways ${ }^{59}$. Zoller and Clark were the first to report laboratory evidence of bacterial production of volatiles ${ }^{60}$. Many classification systems exist for microbial volatiles with one potential system categorising them into fatty acid derivatives, aromatic compounds, nitrogen-containing compounds, sulphur compounds, terpenoids, halogenated selenium, tellurium and other metalloid compounds ${ }^{61}$. Their production is dependent on the bacterial species, bacterial strains, bacterial growth phase, co-cultures, $\mathrm{pH}$, humidity, nutrients, temperature and other environmental factors ${ }^{62,63}$. The ability to rapidly sample and analyse VOCs, potentially allowing identification of bacteria, has massive implications in the management of infection in clinical settings. 


\section{VOC sampling and analytical techniques}

There are numerous sampling techniques that have been utilised in order to collect and identify VOCs, the advantages and limitations of which are outlined in Figure 1. These include VOC collection onto adsorbents, such as Tenax or solid-phase micro-extraction (SPME) ${ }^{64}$, either directly or through an intermediary such as gauze or cotton pads ${ }^{65}$; collection in sealed containers ${ }^{66}$; direct or indirect solvent extraction ${ }^{67}$; or combinations of the above. The above methods do not often identify all VOCs present due to selective adsorption of the trapping material and these sampling techniques limit accurate quantification of VOCs and therefore direct sampling are utilised ${ }^{68}$.

There are a variety of analytical chemical techniques used in VOC detection (Figure 2). Gas chromatography mass spectrometry (GCMS) is a combined analytical system and is one of the most widely used and powerful analytical chemical methods. It detects and quantifies VOCs over a range from parts per million to part per billion or less. Samples for GCMS must be in the gaseous phase where they are injected into the chromatograph where an inert carrier gas transports it though a tubular column. The length of the columns used varies with longer columns providing better chromatographic resolution and maximum separation of analytes. Each compound is emitted from the column at different times with the mass spectrometer used to detect eluting compounds through compound ionisation followed by measurement of the mass to charge ratio of each ion generating a unique mass spectrum for the compound ${ }^{69}$. The major advantages of GCMS are increased sensitivity and compound identification is greatly facilitated by the availability of extensive and easily searchable databases ${ }^{70}$. However, it is not typically strong at identifying unknown compounds. Other limitations of GCMS are increased processing and analysis times and similarity of molecular fragmentation 
patterns from structural isomers can make compound identification difficult ${ }^{71}$. Also, due to high detection limits, sample pre-concentration using techniques described above are typically required, making quantification of VOCs very difficult. A time of flight (TOF) mass spectrometer serves a very similar purpose to GCMS with the exception of providing a combination of high mass accuracy and extended range of detectable metabolites ${ }^{72}$.

Ion mobility spectrometry (IMS) separates gas-phase ions based on their size and shape ${ }^{73}$. This technology has long been used in the detection of explosives and illegal substances ${ }^{74}$. It can be coupled to a pre-separating multi capillary column (MCC) unit allowing twodimensional volatile separation, significantly increasing the resolution of metabolites ${ }^{75}$. MCC allows minimisation or avoidance of analyte interactions in the ionisation region of the IMS, thus reducing the complexity of the measurement signal ${ }^{76}$. IMS is advantageous over GCMS as ambient air can be used as the carrier gas, eliminating the need for a pure speciality inert gas or a vacuum. This has allowed IMS to be portable and provide on-site measurements. IMS is highly sensitive with very low detection limits between the parts per billion to parts per trillion ranges, offers excellent low detection limits and gives relatively rapid results ${ }^{77}$. IMS is however not suitable for identification of unknown compounds.

Direct injection mass spectrometry methods include ion molecule reaction mass spectrometry (IMR-MS), secondary electrospray ionisation mass spectrometry (SESI-MS), selected ion flow tube mass spectrometry (SIFT-MS) and proton transfer reaction mass spectrometry (PTR-MS). A drawback of conventional mass spectrometry instrumentation is the high fragmentation of molecules in a complex gas mixture secondary to high electron ionisation leading to complex mass spectra with overlapping intensities, thus making quantification 
difficult or impossible. IMR-MS offers a very soft from of ionisation leading to less fragmentation. SESI-MS utilises electrospray ionisation technique in order to produce analytes suitable for mass analysis. In PTR-MS, compounds are ionised via proton transfer prior to analysis. This involves the production of $\mathrm{H}_{3} \mathrm{O}^{+}$ions from high purity distilled water through a cathode ion source. SIFT-MS is similar to PTR-MS but is able to ionise a wider range of analytes as it uses a greater number of precursor ions $\left(\mathrm{H}_{3} 0^{+}, \mathrm{NO}^{+}\right.$or $\left.\mathrm{O}_{2}^{+}\right)$for chemical ionisation ${ }^{69}$. The major advantage of direct injection methods is quantification. These direct methods also have lower detection limits than GCMS at parts per trillion ranges. They also provide real-time detection with no sample preparation or separation requirements. They are however limited in the range of VOCs detected compared to GCMS and PTR-MS is limited to the identification of compounds with a higher proton affinity than water.

The electronic nose devices constitute a non-invasive technique capable of detecting and differentiating VOC patterns based on its ability to detect odour. The Cyranose 320 and E50835 electronic nose devices have been used in bacterial identification. These devices allow imprinting of an odour on its sensor chip micro-array which is composed of complex materials. When the sensors are exposed to a gas, the polymer absorbs the gas and swells, during which the distance between the conductive carbon particles increases and thus also increases the resistance of the sensor material ${ }^{78}$. This change in resistance is transmitted to a computer with the pattern of change in the sensor array being used to detect the gas. Electronic nose devices are powerful at differentiating between non-identical samples, provide rapid results with on-site sampling. They are however limited due to temperature and humidity sensitivity, only detect patterns of VOCs programmed on their database and are not suitable for screening of unknown compounds. 


\section{VOCs produced by microorganisms commonly associated with wound infection}

This section details the VOCs identified from the common causative bacteria of wounds based on the different analytical techniques available. With regards to VOC quantities, based on analytical technique used studies varied with some presenting relative abundances whereas others identified absolute concentrations of compounds. The majority of studies have provided VOC abundances relative to other compounds identified ${ }^{79-84}$. Studies where absolute abundances of VOCs are shown range from the parts per million volume to parts per trillion volume ${ }^{85-87}$. Parts per million volume concentrations equate to $\mu \mathrm{g} / \mathrm{l}$ sampled, parts per billion volume concentrations equate to $\mathrm{ng} / \mathrm{l}$ sampled and parts per trillion volume concentrations equate to $\mathrm{pg} / \mathrm{l}$ sampled. Studies in which more than 5 VOCs were identified for a specific bacterial species, only the top 5 compounds based on abundance (either relative or absolute) are presented (table 1). Studies where VOC production could not be attributed to an isolated bacterial species or strain were excluded.

Informatics approaches also varied between the studies evaluated. Four main methods were used to confirm identification of VOCs. Some studies compared mass spectra to reference libraries and databases, such as the National Institute of Standards and Technology (NIST) ${ }^{83 \text {, }}$ ${ }^{88}$, Wiley ${ }^{89}$ and Massbank ${ }^{90}$ libraries and pre-determined reference databases ${ }^{91}$. Other studies compared mass spectra and peak retention times with those obtained from pure standard compounds ${ }^{82,85,92}$. The majority of studies combined the use of reference libraries and pure standard compounds for identification of VOCs ${ }^{79,81,86,87,89,93-97}$. A third technique used was the manual comparison of mass spectra with those available in the literature ${ }^{94}$. Lastly, due to the limitations of certain analytical techniques in compound identification, concurrent techniques were utilised to confirm VOC identity ${ }^{76,98-101}$. 


\section{GCMS}

Neerincx et al inoculated $P$. aeruginosa in brain heart infusion broth and sampled the headspace using Tenax TA at 16, 24 and 48 hours ${ }^{93}$. The top 5 VOCs emitted from $P$. aeruginosa cultures were methyl thiolacetate, 2,3-dimethyl-5-isopentylpyrazine, 2-methyl-3(2-propenyl)-pyrazine, 3-methyl-1 H-pyrrole and 6-tridecane. Scholler et al sampled volatile metabolites emitted from $P$. aeruginosa by diffusive sampling again using Tenax ${ }^{89}$. The major headspace VOC identified was dimethyl disulphide. Bean et al were the first to report the application of two-dimensional GC-TOF spectrometry to identify volatiles of $P$. aeruginosa grown for 24 hours in lysogeny broth in sealed GC headspace vials via SPME passive sampling ${ }^{88}$. This method facilitated the identification of 56 VOCs emitted by $P$. aeruginosa of which 28 were new including alcohols, heteroaromatics, ketones, benzenes and aldehydes ${ }^{88}$.Scott-Thomas et al used similar SPME sampling of the headspace of $P$. aeruginosa and found high concentrations of 2-aminoacetophenone ${ }^{84}$.

Saranya et al identified 2-[3-acetoxy-4,4,14-trimethylandrost-8-en-17-yl] propanoic acid was specific to Staphylococcus ${ }^{80}$ and 3-methyl-1-butanol, 2-methylbutanal, 3-methyl-1-butanol, 3-methylbutanoic acid and 2-methylbutanoic acid have been found to be significantly expressed in the headspace of $S$. epidermidis using the purge and trap technique ${ }^{79}$.

Indole is produced by both pathogenic and non-pathogenic strains of E. coli cultured on a mixture of trypticase soy agar and brain heart infusion broth ${ }^{86}$. Bianchi et al inoculated commercial tins of peeled tomatoes with E. coli and found the most abundant compounds detected were dimethylsulfide, 6-methyl-5-hepten-2-one, ethanol, ethyl acetate and 3-methyl 
furan ${ }^{81}$. Umber et al identified differing volatile signatures of $E$. coli dependant on the environment. Headspace analysis revealed E. coli inoculated whole blood released a different set of VOCs compared to $E$. coli cultured in Luria Bertani (LB) broth ${ }^{85}$. VOCs specific to $E$. coli-infected whole blood were dimethyl sulfide, carbon disulphide, ethanol, acetaldehyde and methyl butanoate. Whereas dimethyl disulfide, dimethyl trisulfide, methyl propanoate, 1propanol and methylcyclohexane were isolated only from E.coli cultured in LB broth ${ }^{85}$.

Filipiak et al cultured $S$. aureus and $P$. aeruginosa in tryptic soy broth medium and collected headspace samples on multi-bed sorption tubes ${ }^{87}$. S. aureus released 32 VOCs and P. aeruginosa 37 of diverse chemical classes comprising aldehydes, alcohols, ketones, acids, sulphur containing compounds, esters, hydrocarbons and nitrogen containing compounds. They found distinct differences in the bacteria-specific VOC profiles, especially with regard to aldehydes which were observed by $S$. aureus with no release observed from $P$. aeruginosa 87. Preti et al sampled the headspace of P. aeruginosa and $S$. aureus cultured in blood agar medium in petri culture dishes and identified compounds specific to each species ${ }^{94}$.

Zscheppank et al utilised a novel needle trap technique consisting of a sorbent packed needle to sample headspace of $E$. coli and P. aeruginosa cultured in liquid media ${ }^{102}$ and found both organisms produced isoprene ${ }^{82}$.

Elgaali et al utilised purge and trap and passive SPME sampling of the headspace to analyse E. coli and S. aureus ${ }^{95}$. Both sampling techniques identified indole as the principle component over the headspace of $E$. coli and the purge and trap technique identified long 
chain alcohols, 2-methylbutanol and 3-methylbutanol in abundance, whereas, passive SPME sampling of the headspace identified 2-tridecenone and dimethyldisulfide over the headspace of $S$. aureus ${ }^{95}$.

Boots et al sampled the bacterial headspace, using desorption tubes packed with carbograph 1TD/Carbopack X, of S. aureus, methicillin-resistant S. aureus (MRSA), P. aeruginosa and E. coli cultured in a variety of agars and broths ${ }^{83}$. Samples were analysed by GC-TOF-MS. They identified 25 VOCs which could be used to discriminate between the bacterial strains. They also found 1,1,2,2-tetrachloroethane, 2-heptanone and 1,4-dichlorobenzene are differentially excreted in the headspace of $S$. aureus and MRSA, with the latter two compounds significantly more abundant over the headspace of $M R S A{ }^{83}$.

\section{IMS}

Maddula et al utilised MCC-IMS to identify ethanol, heptan-2-one, and nonan-2-one emitted from the headspace of E. coli cultures ${ }^{76}$. Guaman et al evaluated IMS and GCMS in the detection of VOCs in the breath of rats injected intraperitoneally with E. coli or regular saline after 24 hours and found IMS had a higher sensitivity and specificity than GCMS in distinguishing the two groups ${ }^{98}$. Kunze et al analysed using MCC-IMS the headspace of $E$. coli and P. aeruginosa cultured in Lysogeny Broth and found six VOCs (Decan-1-ol, Ethanol, Indole, Octan-1-ol [monomer and dimer] and $\left.\mathrm{P}_{-} 755 \_105\right)$ exclusively over the headspace of E. coli cultures and 7 VOCs (2-Propanone, Azane [dimer], Dodecane, 2Ethylhexan-1-ol, P_603_25, P_648_36 and P_778_4) emitted exclusively by $P$. aeruginosa cultures ${ }^{91}$. 


\section{Direct injection mass spectrometry}

Only a single study to date has utilised IMR-MS to analyse the headspace over E. faecalis, $S$. aureus and S. epidermidis cultured in blood agar and brain heart infusion broth ${ }^{92}$. They were able to differentiate between the species based on the mass spectra generated from the VOCs.

Zhu et al were the first to report the application of SESI-MS to the detection and characterisation of VOCs produced by $P$. aeruginosa, $S$. aureus and E. coli cultured in tryptic soy broth ${ }^{90}$. They identified $P$. aeruginosa emitted ethanol and 4-Methylphenol in high abundance; S. aureus emitted high concentrations of butanol, acetone and acetic acid; E. coli principle emitted volatile was indole. A follow on study by the same group were able to distinguish 11 strains of E. coli from S. aureus based on VOCs ${ }^{103}$. In addition they identified 6 VOC biomarkers that were common in all E. coli strains.

Carroll et al cultured different strains of $P$. aeruginosa on blood agar and pseudomonasselective media and analysed the headspace using SIFT-MS ${ }^{104}$. They identified the majority of strains emitted high quantities of ammonia and hydrogen cyanide compared to controls. Shestivska et al corroborated the latter findings using both GCMS and SIFT-MS ${ }^{96}$. They also identified a second compound, methyl thiocyanate, is commonly emitted from the majority of P. aeruginosa strains and most probably both compounds are biochemically associated. A follow on study by the same group identified differing production rates of VOC by genotypically different strains of $P$. aeruginos ${ }^{97}$, which may allow differentiation between not only bacterial species but also strains of the same organism. Gilchrist et al identified elevated concentrations of hydrogen cyanide in the breath of patients with chronic $P$. 
aeruginosa infections compared to controls ${ }^{105}$. However, it must be noted that the patients and controls may have been colonised by other bacteria. Allardyce et al inoculated blood culture bottles, supplemented with tryptic soy broth, with isolated strains of P. aeruginosa, $S$. aureus and E. coli and analysed emitted VOCs using SIFT-MS at 6 hours ${ }^{106}$. Nine VOCs in total were assessed to differentiate between the bacterial strains. $P$. aeruginosa cultures had relatively high absolute concentrations of acetic acid and acetone; E. coli ethanol and acetaldehyde; and S. aureus ethanol and acetone ${ }^{106}$. Storer et al used SIFT-MS to measure volatiles emitted from the headspace of urine samples inoculated with $P$. aeruginosa, $S$. aureus, S. epidermidis, E. coli and E. faecalis at 6 hours ${ }^{107}$. The principle VOC emitted compared to non-inoculated samples was formaldehyde for E. coli, ethanol for P. aeruginosa and ammonia for S. epidermidis, S. aureus and E. faecalis. In contrast, Sovova et al found the principle volatile emitted from the headspace of $E$. coli cultured in nutrient broth enriched with glucose was ethanol ${ }^{108}$. This could be explained by the use of different media, strains and growth conditions between the studies. This assumption is confirmed by Chippendale et al who analysed the VOC from the headspace of $E$. coli cultured in two different media ${ }^{109}$. E. coli cultured in Dulbecco's modified Eagle's medium resulted in large amounts of ethanol, acetaldehyde and hydrogen sulphide production, whereas E. coli cultured in lysogeny broth, ammonia was the major volatile compound ${ }^{109}$.

Lechner et al used PTR-MS to analyse the headspace of E. coli, P. aeruginosa and S. aureus cultured in either MacConkey agar or Mannitol-salt agar ${ }^{99}$. They identified patterns which were specific to the bacterial species however did not expand on the identity of the VOCs. Using PTR-MS, O'Hara and Mayhew analysed the headspace of $S$. aureus cultured in three different broths (nutrient, dextrose and brain heart bovine) and found although the VOCs emitted were specific to $S$. aureus, their concentrations differed dependant on the type of 
media they were grown in ${ }^{100}$. Both Luchner et al ${ }^{101}$ and Bunge et al ${ }^{110}$ have utilised PTRMS to identify volatiles in the headspace of E. coli.

\section{Electronic nose}

The Cyransose 320 and E50835 electronic nose devices have been utilised to differentiate between $P$. aeruginosa, $S$. aureus and E. coli isolates based on VOC patterns from the headspace ${ }^{81,111-113}$. However, it does not provide details regarding the individual volatile compounds emitted by the bacteria. 


\section{Skin and VOCs}

Skin is the largest human organ ${ }^{114}$ and forms an essential barrier between the body and the environment, protects from injury and provides vital homeostatic mechanisms including control of temperature, maintenance of fluid balance, and detection of sensations such as pain 115. A compilation of 1840 VOCs emitted from healthy human individuals has recently been published with skin containing 532 different compounds ${ }^{19}$. The origins of VOCs emanating from skin are either from eccrine, sebaceous, and apocrine glandular secretions or metabolism of the skin microbiota ${ }^{67,116-119}$ (Figure 3). VOCs released from skin are diverse including ketones, aldehydes, heterocyclic compounds, hydrocarbons, terpenes, esters, volatile sulphur compounds and alcohols ${ }^{66,67,120-122}$. VOCs emitted from skin are affected by environmental factors such as diet and use of fragranced products such as soaps and perfumes 123. This makes study design difficult with studies to date varying on the protocol with regards to skin preparation prior to volatile extraction. Some have asked subjects to make no changes ${ }^{124}$, others have stipulated the avoidance of fragranced products ${ }^{67}$, whilst others have implemented dietary restrictions ${ }^{125,}{ }^{126}$. Studies examining the skin volatilome have employed different sampling techniques. These include solvent extraction, dynamic headspace absorption indirectly or directly onto absorbent traps, trapping tubes allowing direct insertion into the GC and SPME ${ }^{68,119,127-130}$. Each has their advantages and limitations including isolation of unexpected VOCs, exogenous contamination and loss of low molecular weight volatiles (Figure 1) ${ }^{64}$.

The top 5 VOCs identified from human skin are 6- methyl-5-hepten-2-one, nonanal, decanal, geranylacetone and (E)-2-nonenal ${ }^{64}$. Harraca et al analysed the VOCs of the whole human body by collection through customised heat sealed oven bags which participants wore from 
the neck down and found the main compounds were heptanal, octanal, nonanal, decanal, 6methyl-5-hepten-2-one and geranylacetone ${ }^{126}$. The array of VOCs emitted from human skin also varies according to the body site sampled (Figure 4). Axillary sampling has revealed high concentrations of alkanes, C6-C11 carboxylic acids, 3-methyl-2-hexenoic acid and 3hydroxy-3-methylhexanoic acid ${ }^{119,127,131}$. However, different sampling techniques have led to a different array of volatiles identified ${ }^{128}$. VOCs emitted from the hands often consist of aldehydes and ketones ${ }^{64}$ and in addition forearm volatiles also comprise of alkanes and carboxylic acids ${ }^{67}$. The main volatiles released from feet are carboxylic acids ${ }^{132,133}$. Ageing also seems to have an effect on VOC profiles of skin with four potential markers of ageing namely (E)-2-nonenal, dimethylsulphone, benzothiazole, and nonanal identified ${ }^{67,134}$.

VOCs emitted from the skin have been studied as potential markers of disease. VOC patterns from skin melanoma have been identified using electronic nose devices ${ }^{135}$ and Kwak et al employed headspace SPME-GCMS to identify specific volatiles that could differentiate between melanoma and normal melanocyte cells cultured in vitro ${ }^{136}$. They found melanoma cells emit dimethyl disulfide and dimethyl trisulfide along with higher concentrations of isoamyl alcohol compared to normal melanocytes. Abaffy et al reported 3 studies utilising headspace SPME-GCMS for the differentiation of melanoma in vivo ${ }^{137-139}$. Firstly they identified 4-methyl decane, dodecane and undecane were preferentially expressed in melanoma fresh and frozen tissue samples compared to control skin ${ }^{137}$. In a follow on case study they found 32 VOCs of which 23 were only detected from melanoma lesions compared to normal skin in the same individual ${ }^{138}$. They later followed this on with a pilot study in which they recruited 5 patients with melanoma and 5 patients with benign skin lesions and found increased levels of the fatty acids lauric acid and palmitic acid in melanoma ${ }^{139}$. The detection of VOCs from skin has also been applied experimentally to detect heart failure and 
diabetes ${ }^{140,141}$. Voss et al utilised an electronic nose device to detect emitted VOCs from skin and were able to discriminate between heart failure patients and controls with an accuracy of $87 \%{ }^{140}$. Turner et al used SIFT-MS to carry out a pilot study on five volunteers to determine VOC changes from skin before and after the ingestion of glucose in the fasting state ${ }^{141}$. VOCs were collected in a collection bag surrounding part of the arm and changes in acetone were noted post ingestion of glucose compared to the fasting state ${ }^{141}$. 


\section{Wounds, SSIs and VOCs}

There are no studies published to date investigating the use of VOC detection in the diagnosis of SSIs. The evidence of VOCs emitted from cutaneous wounds is sparse with only two in vivo studies to date. Parry et al utilised an electronic nose device which was able to differentiate between uninfected venous leg wounds and those infected with beta-Haemolytic streptococci ${ }^{142}$. Thomas et al obtained VOC samples from 5 patients with chronic lower limb wounds using a polydimethylsilicone membrane and analysed by gas chromatography ion trap mass spectrometry ${ }^{143}$. They sampled from the wound, boundary areas around the wound and normal skin. They identified an array of VOCs which were unique to each of the sampled sites. They found significant differences in the VOC profile between normal skin and boundary skin and between normal skin and wounded skin but showed no difference between boundary skin and wound profiles. They recognised 6 compounds which may be responsible for this difference: 1-(1-methyethoxy) 2-propanol; dimethyl disulfide; 3-carene; 2-ethyl-1hexanol; 3,5-bis(1,1-dimethylethyl)-phenol; and butylated hydroxytoluene. These compounds are often associated with preservatives found in creams and gels. However, they do elucidate that their protocol restricted the use of such creams and gels and that none of the patients reported using such products during the study period. Although study numbers were small, they provided a basis on which to develop further studies to identify the role of VOCs in wound healing. Dini et al captured the volatiles emitted from compressed and noncompressed body regions using GCMS and an electronic nose device ${ }^{144}$. Their main aim was to identify if the pattern of volatiles emitted differed dependant on skin pressure which would allow the potential identification of patients at risk of developing decubitus wounds. They found emissions from compressed tissue differed from those of non-compressed tissue allowing the potential to be able to non-invasively detect those at risk of developing wounds 144. 


\section{Conclusions and future perspectives}

VOCs emitted by microorganisms commonly associated with cutaneous wound infections are diverse. Studies isolating these pathogens have allowed the identification of potential combinations of volatiles which may allow detection of their presence. Although there are many VOCs that are shared between microorganisms, there are those identified to be unique to particular bacteria (table 2). This knowledge is imperative if VOC detection is to be developed not only to identify if a wound is infected or not but differentiate between causative microorganisms. Although it must be considered that the majority of studies have only investigated the VOC profile of a limited number of species and strains and this may not hold true when extrapolating this to significantly more species and strains.

Studies looking at the same organism have found different patterns of volatiles detected most probably explained by the use of different sampling methods and analytical techniques. Identifying and using the best suited sampling and analytical techniques will be critical. Although there is a wide spectrum of VOCs attributed to the presence of bacteria such as $P$. aeruginosa and E. coli, there is paucity in information available with regards to others such as MRSA, E. faecalis and S. pyogenes. Also of note is that the methodology of the studies thus far employed the use of various media and broths which are not ideal models for skin and cutaneous wounds. Therefore, one must be wary of inferring which volatiles will be emitted by organisms in skin and wounds by extrapolating the findings from these studies. Also, the in vitro studies discussed above have all identified VOCs specific to bacterial species in the planktonic phase. Extrapolating this to the identification of the bio-burden in a biofilm state must be approached with caution as the presence of other biofilm components such as the extracellular polymeric substance may alter the VOC profile. Therefore, future 
studies must compare the VOC profiles of bacterial species in both their planktonic and biofilm states.

In vivo studies assessing VOCs released from skin have identified a vast array of volatiles in both health and disease with potential markers of cutaneous malignancy and other common diseases identified. However, studies again have varied with regards to sampling methods which have proved much more difficult compared to in vitro experimental sampling. Also, controlling for external factors have proven difficult in human subjects leading to identification of exogenous and contaminant VOCs despite robust attempts to minimise this. Information with regards to VOCs emitted from cutaneous wounds is very limited; however the couple of studies to date have provided a direction for future work.

Current laboratory-based techniques - culture and non-culture based techniques - are timeconsuming and culture over-estimates rapidly dividing non-fastidious bacteria and underestimates more fastidious anaerobes ${ }^{50}$. Molecular methods provide a detailed breakdown of the poly-microbial nature of wounds, however, are deficient in providing information regarding the dominant strain or strains driving the infection. Therefore, the use of untargeted empirical antimicrobial treatment is common based on the limited strain information available, which causes delay in optimal wound management as well as risk for development of antimicrobial resistance. The addition of VOC profiling could provide a more detailed outlook on the development state of a biofilm and on the metabolic processes microorganisms are relying on to thrive in the wound, thus allowing treatment to be specifically tailored. 
With regards to utilising VOC detection techniques in the diagnosis of chronic wound and SSIs, several limitations must be considered. As described above surgical patients undergo risk reducing measures such as peri- and post-operative antimicrobial administration and surgical skin preparation which will alter the wound microbiome. This in turn will alter the microbial metabolites produced and emitted from the wound surface. Also the use of cosmetic and sanitary products which themselves will release VOCs have the potential to interfere and mis-lead. Other significant limitations are the spectrum of surgical wounds ranging from clean to dirty-infected and the phase of bacterial growth will provide a spectrum of microorganisms and therefore a substantially variable array of metabolites produced. Also most chronic wounds are poly-microbial in nature with the presence of different strains of the same species and the presence of more than one active microorganism will produce a different volatile signature compared to its isolated state. Therefore it is vital that any technique used has the capability to detect a multitude of VOCs and the ability to identify poly-microbial infections in order to aid specificity in diagnoses of SSIs.

There are currently no approved tests based on VOC detection in the diagnosis of SSI or cutaneous wound infections. However, there are FDA approved devices available in the diagnosis of asthma ${ }^{145}$, Helicobacter pylori infection ${ }^{146}$ and heart transplant rejection ${ }^{147}$, which are all based on VOC detection. There is currently a huge interest and a developing body of work in the use of VOC detection in the diagnosis and monitoring of various diseases ranging from infection to malignancy ${ }^{148,149}$. Volatile detection via breath testing has been at the forefront in the potential of this concept to diagnose infection. It is controversial whether an organism can be identified by its VOC profile as these are influenced by environmental factors, co-cultures and species strains ${ }^{62}$. However, recent studies on mono- and co-cultures of species in different growth conditions associated with infections in cystic fibrosis patients 
have yielded patterns of VOCs that allowed species identification ${ }^{93,150,151}$. Also, Kunze et al found no difference between VOC patterns of different strains of a single species and concluded that VOC patterns of a bacterial strain can be transferred to other strains of the same species ${ }^{91}$. VOCs also provide information about host-infection interactions and the types of metabolic processes occurring ${ }^{120,152}$. Rather than just species identification, VOC profiling could be used to delineate the stage of infection based on the activation of certain metabolic processes ${ }^{153}$, thus not only allowing identification of infection but allowing the tailoring of treatment of chronic wounds and monitoring treatment response.

We propose the need for further in vitro experimental work and robust clinical studies in order to identify signature volatiles of the common organisms attributed to the aetiology of chronic wounds and SSIs. Culturing these bacteria on skin explants and combining these with substrates such as Matrigel ${ }^{154}$ to allow representation of cutaneous wounds in vitro would allow a more accurate determination of VOCs produced and emitted. Taking this information with volatiles emitted from acute, chronic and surgical wounds in vivo would potentially allow identification of VOCs which could be attributed to infected wounds and normal and abnormal wound healing. The ultimate goal would be to develop a clinical diagnostic tool which is inexpensive, portable, non-invasive, and reliable and offers time efficient results in detecting cutaneous wound infections in order to expedite accurate management. VOC detection has the potential to offer this. 


\section{Acknowledgements}

We would like thank Helen Carruthers for graphical support of this paper.

\section{Conflicts of interest}

None.

\section{Funding}

None. 


\section{References}

1. Guo S, Dipietro LA. Factors affecting wound healing. J Dent Res 2010; 89:219-29.

2. Fonder MA, Lazarus GS, Cowan DA, Aronson-Cook B, Kohli AR, Mamelak AJ. Treating the chronic wound: A practical approach to the care of nonhealing wounds and wound care dressings. J Am Acad Dermatol 2008; 58:185-206.

3. Posnett J, Franks PJ. The burden of chronic wounds in the UK. Nurs Times 2008; 104:44-5.

4. Martin-Granados C, McCaig CD. Harnessing the Electric Spark of Life to Cure Skin Wounds. Adv Wound Care (New Rochelle) 2014; 3:127-38.

5. Penhallow K. A review of studies that examine the impact of infection on the normal wound-healing process. J Wound Care 2005; 14:123-6.

6. Costerton JW, DeMeo P. Discussion. The role of biofilms: are we hitting the right target? Plast Reconstr Surg 2011; 127 Suppl 1:36S-7S.

7. de Lissovoy G, Fraeman K, Hutchins V, Murphy D, Song D, Vaughn BB. Surgical site infection: incidence and impact on hospital utilization and treatment costs. Am J Infect Control 2009; 37:387-97.

8. Mangram AJ, Horan TC, Pearson ML, Silver LC, Jarvis WR. Guideline for prevention of surgical site infection, 1999. Hospital Infection Control Practices Advisory Committee. Infect Control Hosp Epidemiol 1999; 20:250-78; quiz 79-80.

9. Giacometti A, Cirioni O, Schimizzi AM, Del Prete MS, Barchiesi F, D'Errico MM, et al. Epidemiology and microbiology of surgical wound infections. J Clin Microbiol 2000; 38:918-22.

10. Saini S, Gupta N, Aparna, Lokveer, Griwan MS. Surgical infections: a microbiological study. Braz J Infect Dis 2004; 8:118-25.

11. Surucuoglu S, Gazi H, Kurutepe S, Ozkutuk N, Ozbakkaloglu B. Bacteriology of surgical wound infections in a tertiary care hospital in Turkey. East Afr Med J 2005; 82:331-6.

12. Múñez E, Ramos A, Espejo T, Vaqué J, Sánchez-Payá J, Pastor V, et al. [Microbiology of surgical site infections in abdominal tract surgery patients]. Cir Esp 2011; 89:606-12.

13. Grace CJ, Lieberman J, Pierce K, Littenberg B. Usefulness of blood culture for hospitalized patients who are receiving antibiotic therapy. Clin Infect Dis 2001; 32:1651-5.

14. Bates DW, Goldman L, Lee TH. Contaminant blood cultures and resource utilization. The true consequences of false-positive results. JAMA 1991; 265:365-9.

15. Pletz MW, Wellinghausen N, Welte T. Will polymerase chain reaction (PCR)-based diagnostics improve outcome in septic patients? A clinical view. Intensive Care Med 2011; 37:1069-76.

16. Retamar P, Portillo MM, López-Prieto MD, Rodríguez-López F, de Cueto M, García MV, et al. Impact of inadequate empirical therapy on the mortality of patients with bloodstream infections: a propensity score-based analysis. Antimicrob Agents Chemother 2012; 56:472-8.

17. Zlatkis A, Brazell RS, Poole CF. The role of organic volatile profiles in clinical diagnosis. Clin Chem 1981; 27:789-97.

18. Probert CS, Ahmed I, Khalid T, Johnson E, Smith S, Ratcliffe N. Volatile organic compounds as diagnostic biomarkers in gastrointestinal and liver diseases. J Gastrointestin Liver Dis 2009; 18:337-43. 
19. de Lacy Costello B, Amann A, Al-Kateb H, Flynn C, Filipiak W, Khalid T, et al. A review of the volatiles from the healthy human body. J Breath Res 2014; 8:014001.

20. Hakim M, Broza YY, Barash O, Peled N, Phillips M, Amann A, et al. Volatile organic compounds of lung cancer and possible biochemical pathways. Chem Rev 2012; 112:5949-66.

21. Xu ZQ, Broza YY, Ionsecu R, Tisch U, Ding L, Liu H, et al. A nanomaterial-based breath test for distinguishing gastric cancer from benign gastric conditions. Br J Cancer 2013; 108:941-50.

22. Hakim M, Billan S, Tisch U, Peng G, Dvrokind I, Marom O, et al. Diagnosis of head-and-neck cancer from exhaled breath. Br J Cancer 2011; 104:1649-55.

23. Phillips M, Cataneo RN, Saunders C, Hope P, Schmitt P, Wai J. Volatile biomarkers in the breath of women with breast cancer. J Breath Res 2010; 4:026003.

24. Amal H, Ding L, Liu BB, Tisch U, Xu ZQ, Shi DY, et al. The scent fingerprint of hepatocarcinoma: invitro metastasis prediction with volatile organic compounds (VOCs). Int J Nanomedicine 2012; 7:4135-46.

25. Xue R, Dong L, Zhang S, Deng C, Liu T, Wang J, et al. Investigation of volatile biomarkers in liver cancer blood using solid-phase microextraction and gas chromatography/mass spectrometry. Rapid Commun Mass Spectrom 2008; 22:1181-6.

26. Peng G, Hakim M, Broza YY, Billan S, Abdah-Bortnyak R, Kuten A, et al. Detection of lung, breast, colorectal, and prostate cancers from exhaled breath using a single array of nanosensors. Br J Cancer 2010; 103:542-51.

27. Olopade CO, Zakkar M, Swedler WI, Rubinstein I. Exhaled pentane levels in acute asthma. Chest 1997; 111:862-5.

28. Paredi P, Kharitonov SA, Barnes PJ. Elevation of exhaled ethane concentration in asthma. Am J Respir Crit Care Med 2000; 162:1450-4.

29. Montuschi P, Corradi M, Ciabattoni G, Nightingale J, Kharitonov SA, Barnes PJ. Increased 8isoprostane, a marker of oxidative stress, in exhaled condensate of asthma patients. Am J Respir Crit Care Med 1999; 160:216-20.

30. Van Berkel JJ, Dallinga JW, Möller GM, Godschalk RW, Moonen E, Wouters EF, et al. Development of accurate classification method based on the analysis of volatile organic compounds from human exhaled air. J Chromatogr B Analyt Technol Biomed Life Sci 2008; 861:101-7.

31. Kanoh S, Kobayashi H, Motoyoshi K. Exhaled ethane: an in vivo biomarker of lipid peroxidation in interstitial lung diseases. Chest 2005; 128:2387-92.

32. Kokoszka J, Nelson RL, Swedler WI, Skosey J, Abcarian H. Determination of inflammatory bowel disease activity by breath pentane analysis. Dis Colon Rectum 1993; 36:597-601.

33. Pelli MA, Trovarelli G, Capodicasa E, De Medio GE, Bassotti G. Breath alkanes determination in ulcerative colitis and Crohn's disease. Dis Colon Rectum 1999; 42:71-6.

34. Novak BJ, Blake DR, Meinardi S, Rowland FS, Pontello A, Cooper DM, et al. Exhaled methyl nitrate as a noninvasive marker of hyperglycemia in type 1 diabetes. Proc Natl Acad Sci U S A 2007; 104:15613-8.

35. Galassetti PR, Novak B, Nemet D, Rose-Gottron C, Cooper DM, Meinardi S, et al. Breath ethanol and acetone as indicators of serum glucose levels: an initial report. Diabetes Technol Ther 2005; 7:115-23. 
36. Graham JE. Bacterial volatiles and diagnosis of respiratory infections. Adv Appl Microbiol 2013; $82: 29-52$.

37. James GA, Swogger E, Wolcott R, Pulcini E, Secor P, Sestrich J, et al. Biofilms in chronic wounds. Wound Repair Regen 2008; 16:37-44.

38. Edmiston CE, McBain AJ, Roberts C, Leaper D. Clinical and microbiological aspects of biofilmassociated surgical site infections. Adv Exp Med Biol 2015; 830:47-67.

39. Cheadle WG. Risk factors for surgical site infection. Surg Infect (Larchmt) 2006; 7 Suppl 1:S7-11.

40. Watanabe A, Kohnoe S, Shimabukuro R, Yamanaka T, Iso Y, Baba H, et al. Risk factors associated with surgical site infection in upper and lower gastrointestinal surgery. Surg Today 2008; 38:404-12.

41. Chen CC, Collins SA, Rodgers AK, Paraiso MF, Walters MD, Barber MD. Perioperative complications in obese women vs normal-weight women who undergo vaginal surgery. Am J Obstet Gynecol 2007; 197:98.e1-8.

42. Sorensen LT, Karlsmark T, Gottrup F. Abstinence from smoking reduces incisional wound infection: a randomized controlled trial. Ann Surg 2003; 238:1-5.

43. Zerr KJ, Furnary AP, Grunkemeier GL, Bookin S, Kanhere V, Starr A. Glucose control lowers the risk of wound infection in diabetics after open heart operations. Ann Thorac Surg 1997; 63:356-61.

44. Mangram AJ, Horan TC, Pearson ML, Silver LC, Jarvis WR. Guideline for Prevention of Surgical Site Infection, 1999. Centers for Disease Control and Prevention (CDC) Hospital Infection Control Practices Advisory Committee. Am J Infect Control 1999; 27:97-132; quiz 3-4; discussion 96.

45. Cruse PJ, Foord R. The epidemiology of wound infection. A 10-year prospective study of 62,939 wounds. Surg Clin North Am 1980; 60:27-40.

46. Culver DH, Horan TC, Gaynes RP, Martone WJ, Jarvis WR, Emori TG, et al. Surgical wound infection rates by wound class, operative procedure, and patient risk index. National Nosocomial Infections Surveillance System. Am J Med 1991; 91:152S-7S.

47. Reichman DE, Greenberg JA. Reducing surgical site infections: a review. Rev Obstet Gynecol 2009; $2: 212-21$.

48. Kostakioti M, Hadjifrangiskou M, Hultgren SJ. Bacterial biofilms: development, dispersal, and therapeutic strategies in the dawn of the postantibiotic era. Cold Spring Harb Perspect Med 2013; 3:a010306.

49. Edwards R, Harding KG. Bacteria and wound healing. Curr Opin Infect Dis 2004; 17:91-6.

50. Wolcott RD, Ehrlich GD. Biofilms and chronic infections. JAMA 2008; 299:2682-4.

51. Gristina AG, Price JL, Hobgood CD, Webb LX, Costerton JW. Bacterial colonization of percutaneous sutures. Surgery 1985; 98:12-9.

52. Kathju S, Nistico L, Melton-Kreft R, Lasko LA, Stoodley P. Direct demonstration of bacterial biofilms on prosthetic mesh after ventral herniorrhaphy. Surg Infect (Larchmt) 2015; 16:45-53.

53. Høiby N, Ciofu O, Johansen HK, Song ZJ, Moser C, Jensen P, et al. The clinical impact of bacterial biofilms. Int J Oral Sci 2011; 3:55-65.

54. Akers KS, Mende K, Cheatle KA, Zera WC, Yu X, Beckius ML, et al. Biofilms and persistent wound infections in United States military trauma patients: a case-control analysis. BMC Infect Dis 2014; 14:190. 
55. Barnes S, Spencer M, Graham D, Johnson HB. Surgical wound irrigation: a call for evidence-based standardization of practice. Am J Infect Control 2014; 42:525-9.

56. Edmiston CE, Bruden B, Rucinski MC, Henen C, Graham MB, Lewis BL. Reducing the risk of surgical site infections: does chlorhexidine gluconate provide a risk reduction benefit? Am J Infect Control 2013; 41:S49-55.

57. Barber KE, Werth BJ, McRoberts JP, Rybak MJ. A novel approach utilizing biofilm time-kill curves to assess the bactericidal activity of ceftaroline combinations against biofilm-producing methicillinresistant Staphylococcus aureus. Antimicrob Agents Chemother 2014; 58:2989-92.

58. Romano A, Capozzi V, Spano G, Biasioli F. Proton transfer reaction-mass spectrometry: online and rapid determination of volatile organic compounds of microbial origin. Appl Microbiol Biotechnol 2015; 99:3787-95.

59. Tait E, Perry JD, Stanforth SP, Dean JR. Identification of volatile organic compounds produced by bacteria using HS-SPME-GC-MS. J Chromatogr Sci 2014; 52:363-73.

60. Zoller HF, Clark WM. THE PRODUCTION OF VOLATILE FATTY ACIDS BY BACTERIA OF THE DYSENTERY GROUP. J Gen Physiol 1921; 3:325-30.

61. Schulz S, Dickschat JS. Bacterial volatiles: the smell of small organisms. Nat Prod Rep 2007; 24:81442.

62. Korpi A, Järnberg J, Pasanen AL. Microbial volatile organic compounds. Crit Rev Toxicol 2009; 39:139-93.

63. Heddergott C, Calvo AM, Latgé JP. The volatome of Aspergillus fumigatus. Eukaryot Cell 2014; 13:1014-25.

64. Dormont L, Bessière JM, Cohuet A. Human skin volatiles: a review. J Chem Ecol 2013; 39:569-78.

65. Jiang R, Cudjoe E, Bojko B, Abaffy T, Pawliszyn J. A non-invasive method for in vivo skin volatile compounds sampling. Anal Chim Acta 2013; 804:111-9.

66. Mochalski P, King J, Unterkofler K, Hinterhuber H, Amann A. Emission rates of selected volatile organic compounds from skin of healthy volunteers. J Chromatogr B Analyt Technol Biomed Life Sci 2014; 959:62-70.

67. Gallagher M, Wysocki CJ, Leyden JJ, Spielman AI, Sun X, Preti G. Analyses of volatile organic compounds from human skin. Br J Dermatol 2008; 159:780-91.

68. Martínez-Lozano P, de la Mora JF. On-line detection of human skin vapors. J Am Soc Mass Spectrom 2009; 20:1060-3.

69. Beale DJ, Jones OA, Karpe AV, Dayalan S, Oh DY, Kouremenos KA, et al. A Review of Analytical Techniques and Their Application in Disease Diagnosis in Breathomics and Salivaomics Research. Int J Mol Sci 2016; 18.

70. Sweetlove LJ, Last RL, Fernie AR. Predictive metabolic engineering: a goal for systems biology. Plant Physiol 2003; 132:420-5.

71. Jones OA, Cheung VL. An introduction to metabolomics and its potential application in veterinary science. Comp Med 2007; 57:436-42.

72. Hall R, Beale M, Fiehn O, Hardy N, Sumner L, Bino R. Plant metabolomics: the missing link in functional genomics strategies. Plant Cell 2002; 14:1437-40. 
73. Eiceman GA, Bergloff JF, Rodriguez JE, Munro W, Karpas Z. Atmospheric pressure chemical ionization of fluorinated phenols in atmospheric pressure chemical ionization mass spectrometry, tandem mass spectrometry, and ion mobility spectrometry. J Am Soc Mass Spectrom 1999; 10:115765.

74. D'Agostino PA, Chenier CL. Desorption electrospray ionization mass spectrometric analysis of organophosphorus chemical warfare agents using ion mobility and tandem mass spectrometry. Rapid Commun Mass Spectrom 2010; 24:1617-24.

75. Baumbach JI, Eiceman GA. Ion mobility spectrometry: arriving on site and moving beyond a low profile. Appl Spectrosc 1999; 53:338A-55A.

76. Maddula S, Blank LM, Schmid A, Baumbach JI. Detection of volatile metabolites of Escherichia coli by multi capillary column coupled ion mobility spectrometry. Anal Bioanal Chem 2009; 394:791-800.

77. Baumbach JI. Process analysis using ion mobility spectrometry. Anal Bioanal Chem 2006; 384:105970 .

78. Dragonieri S, Schot R, Mertens BJ, Le Cessie S, Gauw SA, Spanevello A, et al. An electronic nose in the discrimination of patients with asthma and controls. J Allergy Clin Immunol 2007; 120:856-62.

79. Verhulst NO, Beijleveld H, Knols BG, Takken W, Schraa G, Bouwmeester HJ, et al. Cultured skin microbiota attracts malaria mosquitoes. Malar J 2009; 8:302.

80. Saranya R, Aarthi R, Sankaran K. Simple and specific colorimetric detection of Staphylococcus using its volatile 2-[3-acetoxy-4,4,14-trimethylandrost-8-en-17-yl] propanoic acid in the liquid phase and head space of cultures. Appl Microbiol Biotechnol 2015; 99:4423-33.

81. Bianchi F, Careri M, Mangia A, Mattarozzi M, Musci M, Concina I, et al. Differentiation of the volatile profile of microbiologically contaminated canned tomatoes by dynamic headspace extraction followed by gas chromatography-mass spectrometry analysis. Talanta 2009; 77:962-70.

82. Zscheppank C, Wiegand HL, Lenzen C, Wingender J, Telgheder U. Investigation of volatile metabolites during growth of Escherichia coli and Pseudomonas aeruginosa by needle trap-GC-MS. Anal Bioanal Chem 2014; 406:6617-28.

83. Boots AW, Smolinska A, van Berkel JJ, Fijten RR, Stobberingh EE, Boumans ML, et al. Identification of microorganisms based on headspace analysis of volatile organic compounds by gas chromatography-mass spectrometry. J Breath Res 2014; 8:027106.

84. Scott-Thomas AJ, Syhre M, Pattemore PK, Epton M, Laing R, Pearson J, et al. 2-Aminoacetophenone as a potential breath biomarker for Pseudomonas aeruginosa in the cystic fibrosis lung. BMC Pulm Med 2010; 10:56.

85. Umber BJ, Shin HW, Meinardi S, Leu SY, Zaldivar F, Cooper DM, et al. Gas signatures from Escherichia coli and Escherichia coli-inoculated human whole blood. Clin Transl Med 2013; 2:13.

86. Yu K, Hamilton-Kemp TR, Archbold DD, Collins RW, Newman MC. Volatile compounds from Escherichia coli O157:H7 and their absorption by strawberry fruit. J Agric Food Chem 2000; 48:413-7.

87. Filipiak W, Sponring A, Baur MM, Filipiak A, Ager C, Wiesenhofer H, et al. Molecular analysis of volatile metabolites released specifically by Staphylococcus aureus and Pseudomonas aeruginosa. BMC Microbiol 2012; 12:113. 
88. Bean HD, Dimandja JM, Hill JE. Bacterial volatile discovery using solid phase microextraction and comprehensive two-dimensional gas chromatography-time-of-flight mass spectrometry. J Chromatogr B Analyt Technol Biomed Life Sci 2012; 901:41-6.

89. Schöller C, Molin S, Wilkins K. Volatile metabolites from some gram-negative bacteria. Chemosphere 1997; 35:1487-95.

90. Zhu J, Bean HD, Kuo YM, Hill JE. Fast detection of volatile organic compounds from bacterial cultures by secondary electrospray ionization-mass spectrometry. J Clin Microbiol 2010; 48:4426-31.

91. Kunze N, Göpel J, Kuhns M, Jünger M, Quintel M, Perl T. Detection and validation of volatile metabolic patterns over different strains of two human pathogenic bacteria during their growth in a complex medium using multi-capillary column-ion mobility spectrometry (MCC-IMS). Appl Microbiol Biotechnol 2013; 97:3665-76.

92. Dolch ME, Hornuss C, Klocke C, Praun S, Villinger J, Denzer W, et al. Volatile organic compound analysis by ion molecule reaction mass spectrometry for Gram-positive bacteria differentiation. Eur J Clin Microbiol Infect Dis 2012; 31:3007-13.

93. Neerincx AH, Geurts BP, Habets MF, Booij JA, van Loon J, Jansen JJ, et al. Identification of Pseudomonas aeruginosa and Aspergillus fumigatus mono- and co-cultures based on volatile biomarker combinations. J Breath Res 2016; 10:016002.

94. Preti G, Thaler E, Hanson CW, Troy M, Eades J, Gelperin A. Volatile compounds characteristic of sinus-related bacteria and infected sinus mucus: analysis by solid-phase microextraction and gas chromatography-mass spectrometry. J Chromatogr B Analyt Technol Biomed Life Sci 2009; 877:20118 .

95. Elgaali H, Hamilton-Kemp TR, Newman MC, Collins RW, Yu K, Archbold DD. Comparison of longchain alcohols and other volatile compounds emitted from food-borne and related Gram positive and Gram negative bacteria. J Basic Microbiol 2002; 42:373-80.

96. Shestivska V, Nemec A, Dřevínek P, Sovová K, Dryahina K, Spaněl P. Quantification of methyl thiocyanate in the headspace of Pseudomonas aeruginosa cultures and in the breath of cystic fibrosis patients by selected ion flow tube mass spectrometry. Rapid Commun Mass Spectrom 2011; 25:245967.

97. Shestivska V, Spaněl P, Dryahina K, Sovová K, Smith D, Musílek M, et al. Variability in the concentrations of volatile metabolites emitted by genotypically different strains of Pseudomonas aeruginosa. J Appl Microbiol 2012; 113:701-13.

98. Guamán AV, Carreras A, Calvo D, Agudo I, Navajas D, Pardo A, et al. Rapid detection of sepsis in rats through volatile organic compounds in breath. J Chromatogr B Analyt Technol Biomed Life Sci 2012; 881-882:76-82.

99. Lechner M, Fille M, Hausdorfer J, Dierich MP, Rieder J. Diagnosis of bacteria in vitro by mass spectrometric fingerprinting:a pilot study. Curr Microbiol 2005; 51:267-9.

100. O'Hara M, Mayhew CA. A preliminary comparison of volatile organic compounds in the headspace of cultures of Staphylococcus aureus grown in nutrient, dextrose and brain heart bovine broths measured using a proton transfer reaction mass spectrometer. J Breath Res 2009; 3:027001. 
101. Luchner M, Gutmann R, Bayer K, Dunkl J, Hansel A, Herbig J, et al. Implementation of proton transfer reaction-mass spectrometry (PTR-MS) for advanced bioprocess monitoring. Biotechnol Bioeng 2012; 109:3059-69.

102. Asl-Hariri S, Gómez-Ríos GA, Gionfriddo E, Dawes P, Pawliszyn J. Development of needle trap technology for on-site determinations: active and passive sampling. Anal Chem 2014; 86:5889-97.

103. Zhu J, Hill JE. Detection of Escherichia coli via VOC profiling using secondary electrospray ionization-mass spectrometry (SESI-MS). Food Microbiol 2013; 34:412-7.

104. Carroll W, Lenney W, Wang T, Spanel P, Alcock A, Smith D. Detection of volatile compounds emitted by Pseudomonas aeruginosa using selected ion flow tube mass spectrometry. Pediatr Pulmonol $2005 ; 39: 452-6$.

105. Gilchrist FJ, Bright-Thomas RJ, Jones AM, Smith D, Spaněl P, Webb AK, et al. Hydrogen cyanide concentrations in the breath of adult cystic fibrosis patients with and without Pseudomonas aeruginosa infection. J Breath Res 2013; 7:026010.

106. Allardyce RA, Hill AL, Murdoch DR. The rapid evaluation of bacterial growth and antibiotic susceptibility in blood cultures by selected ion flow tube mass spectrometry. Diagn Microbiol Infect Dis 2006; 55:255-61.

107. Storer MK, Hibbard-Melles K, Davis B, Scotter J. Detection of volatile compounds produced by microbial growth in urine by selected ion flow tube mass spectrometry (SIFT-MS). J Microbiol Methods 2011; 87:111-3.

108. Sovová K, Čepl J, Markoš A, Španěl P. Real time monitoring of population dynamics in concurrent bacterial growth using SIFT-MS quantification of volatile metabolites. Analyst 2013; 138:4795-801.

109. Chippendale TW, Španěl P, Smith D. Time-resolved selected ion flow tube mass spectrometric quantification of the volatile compounds generated by E. coli JM109 cultured in two different media. Rapid Commun Mass Spectrom 2011; 25:2163-72.

110. Bunge M, Araghipour N, Mikoviny T, Dunkl J, Schnitzhofer R, Hansel A, et al. On-line monitoring of microbial volatile metabolites by proton transfer reaction-mass spectrometry. Appl Environ Microbiol 2008; 74:2179-86.

111. Shafiek H, Fiorentino F, Merino JL, López C, Oliver A, Segura J, et al. Using the Electronic Nose to Identify Airway Infection during COPD Exacerbations. PLoS One 2015; 10:e0135199.

112. Dutta R, Hines EL, Gardner JW, Boilot P. Bacteria classification using Cyranose 320 electronic nose. Biomed Eng Online 2002; 1:4.

113. Abdallah SA, Al-Shatti LA, Alhajraf AF, Al-Hammad N, Al-Awadi B. The detection of foodborne bacteria on beef: the application of the electronic nose. Springerplus 2013; 2:687.

114. Shores JT, Gabriel A, Gupta S. Skin substitutes and alternatives: a review. Adv Skin Wound Care 2007; 20:493-508; quiz 9-10.

115. Lee SH, Jeong SK, Ahn SK. An update of the defensive barrier function of skin. Yonsei Med J 2006; 47:293-306.

116. Noël F, Piérard-Franchimont C, Piérard GE, Quatresooz P. Sweaty skin, background and assessments. Int J Dermatol 2012; 51:647-55. 
117. Taylor D, Daulby A, Grimshaw S, James G, Mercer J, Vaziri S. Characterization of the microflora of the human axilla. Int J Cosmet Sci 2003; 25:137-45.

118. Natsch A, Gfeller H, Gygax P, Schmid J. Isolation of a bacterial enzyme releasing axillary malodor and its use as a screening target for novel deodorant formulations. Int J Cosmet Sci 2005; 27:115-22.

119. Natsch A, Derrer S, Flachsmann F, Schmid J. A broad diversity of volatile carboxylic acids, released by a bacterial aminoacylase from axilla secretions, as candidate molecules for the determination of human-body odor type. Chem Biodivers 2006; 3:1-20.

120. Amann A, Costello BeL, Miekisch W, Schubert J, Buszewski B, Pleil J, et al. The human volatilome: volatile organic compounds (VOCs) in exhaled breath, skin emanations, urine, feces and saliva. J Breath Res 2014; 8:034001.

121. Mochalski P, Unterkofler K, Hinterhuber H, Amann A. Monitoring of selected skin-borne volatile markers of entrapped humans by selective reagent ionization time of flight mass spectrometry in NO+ mode. Anal Chem 2014; 86:3915-23.

122. Ruzsanyi V, Mochalski P, Schmid A, Wiesenhofer H, Klieber M, Hinterhuber H, et al. Ion mobility spectrometry for detection of skin volatiles. J Chromatogr B Analyt Technol Biomed Life Sci 2012; 911:84-92.

123. Havlicek J, Lenochova P. The effect of meat consumption on body odor attractiveness. Chem Senses 2006; 31:747-52.

124. Bernier UR, Kline DL, Barnard DR, Schreck CE, Yost RA. Analysis of human skin emanations by gas chromatography/mass spectrometry. 2. Identification of volatile compounds that are candidate attractants for the yellow fever mosquito (Aedes aegypti). Anal Chem 2000; 72:747-56.

125. Logan JG, Birkett MA, Clark SJ, Powers S, Seal NJ, Wadhams LJ, et al. Identification of humanderived volatile chemicals that interfere with attraction of Aedes aegypti mosquitoes. J Chem Ecol 2008; 34:308-22.

126. Harraca V, Ryne C, Birgersson G, Ignell R. Smelling your way to food: can bed bugs use our odour? J Exp Biol 2012; 215:623-9.

127. Zeng XN, Leyden JJ, Spielman AI, Preti G. Analysis of characteristic human female axillary odors: Qualitative comparison to males. J Chem Ecol 1996; 22:237-57.

128. Curran AM, Rabin SI, Prada PA, Furton KG. Comparison of the volatile organic compounds present in human odor using SPME-GC/MS. J Chem Ecol 2005; 31:1607-19.

129. Zhang ZM, Cai JJ, Ruan GH, Li GK. The study of fingerprint characteristics of the emanations from human arm skin using the original sampling system by SPME-GC/MS. J Chromatogr B Analyt Technol Biomed Life Sci 2005; 822:244-52.

130. Dormont L, Bessière JM, McKey D, Cohuet A. New methods for field collection of human skin volatiles and perspectives for their application in the chemical ecology of human-pathogen-vector interactions. J Exp Biol 2013; 216:2783-8.

131. Penn DJ, Oberzaucher E, Grammer K, Fischer G, Soini HA, Wiesler D, et al. Individual and gender fingerprints in human body odour. J R Soc Interface 2007; 4:331-40.

132. Ara K, Hama M, Akiba S, Koike K, Okisaka K, Hagura T, et al. Foot odor due to microbial metabolism and its control. Can J Microbiol 2006; 52:357-64. 
133. Caroprese A, Gabbanini S, Beltramini C, Lucchi E, Valgimigli L. HS-SPME-GC-MS analysis of body odor to test the efficacy of foot deodorant formulations. Skin Res Technol 2009; 15:503-10.

134. Haze S, Gozu Y, Nakamura S, Kohno Y, Sawano K, Ohta H, et al. 2-Nonenal newly found in human body odor tends to increase with aging. J Invest Dermatol 2001; 116:520-4.

135. D'Amico A, Bono R, Pennazza G, Santonico M, Mantini G, Bernabei M, et al. Identification of melanoma with a gas sensor array. Skin Res Technol 2008; 14:226-36.

136. Kwak J, Gallagher M, Ozdener MH, Wysocki CJ, Goldsmith BR, Isamah A, et al. Volatile biomarkers from human melanoma cells. J Chromatogr B Analyt Technol Biomed Life Sci 2013; 931:90-6.

137. Abaffy T, Duncan R, Riemer DD, Tietje O, Elgart G, Milikowski C, et al. Differential volatile signatures from skin, naevi and melanoma: a novel approach to detect a pathological process. PLoS One 2010; 5:e13813.

138. Abaffy T, Möller M, Riemer DD, Milikowski C, Defazio RA. A case report - Volatile metabolomic signature of malignant melanoma using matching skin as a control. J Cancer Sci Ther 2011; 3:140-4.

139. Abaffy T, Möller MG, Riemer DD, Milikowski C, DeFazio RA. Comparative analysis of volatile metabolomics signals from melanoma and benign skin: a pilot study. Metabolomics 2013; 9:998-1008.

140. Voss A, Witt K, Fischer C, Reulecke S, Poitz W, Kechagias V, et al. Smelling heart failure from human skin odor with an electronic nose. Conf Proc IEEE Eng Med Biol Soc 2012; 2012:4034-7.

141. Turner C, Parekh B, Walton C, Spanel P, Smith D, Evans M. An exploratory comparative study of volatile compounds in exhaled breath and emitted by skin using selected ion flow tube mass spectrometry. Rapid Commun Mass Spectrom 2008; 22:526-32.

142. Parry AD, Chadwick PR, Simon D, Oppenheim B, McCollum CN. Leg ulcer odour detection identifies beta-haemolytic streptococcal infection. J Wound Care 1995; 4:404-6.

143. Thomas AN, Riazanskaia S, Cheung W, Xu Y, Goodacre R, Thomas CL, et al. Novel noninvasive identification of biomarkers by analytical profiling of chronic wounds using volatile organic compounds. Wound Repair Regen 2010; 18:391-400.

144. Dini F, Capuano R, Strand T, Ek AC, Lindgren M, Paolesse R, et al. Volatile emissions from compressed tissue. PLoS One 2013; 8:e69271.

145. Silkoff PE, Carlson M, Bourke T, Katial R, Ogren E, Szefler SJ. The Aerocrine exhaled nitric oxide monitoring system NIOX is cleared by the US Food and Drug Administration for monitoring therapy in asthma. J Allergy Clin Immunol 2004; 114:1241-56.

146. Graham DY, Klein PD, Evans DJ, Evans DG, Alpert LC, Opekun AR, et al. Campylobacter pylori detected noninvasively by the 13C-urea breath test. Lancet 1987 ; 1:1174-7.

147. Phillips M, Boehmer JP, Cataneo RN, Cheema T, Eisen HJ, Fallon JT, et al. Heart allograft rejection: detection with breath alkanes in low levels (the HARDBALL study). J Heart Lung Transplant 2004; 23:701-8.

148. Wilson $\mathrm{AD}$, Baietto $\mathrm{M}$. Advances in electronic-nose technologies developed for biomedical applications. Sensors (Basel) 2011; 11:1105-76.

149. Modak AS. Regulatory issues on breath tests and updates of recent advances on [13C]-breath tests. J Breath Res 2013; 7:037103. 
150. Neerincx AH, Geurts BP, van Loon J, Tiemes V, Jansen JJ, Harren FJ, et al. Detection of Staphylococcus aureus in cystic fibrosis patients using breath VOC profiles. J Breath Res 2016; 10:046014.

151. Dryahina K, Sovová K, Nemec A, Španěl P. Differentiation of pulmonary bacterial pathogens in cystic fibrosis by volatile metabolites emitted by their in vitro cultures: Pseudomonas aeruginosa, Staphylococcus aureus, Stenotrophomonas maltophilia and the Burkholderia cepacia complex. J Breath Res 2016; 10:037102.

152. Shirasu M, Touhara K. The scent of disease: volatile organic compounds of the human body related to disease and disorder. J Biochem 2011; 150:257-66.

153. Abd El Qader A, Lieberman D, Shemer Avni Y, Svobodin N, Lazarovitch T, Sagi O, et al. Volatile organic compounds generated by cultures of bacteria and viruses associated with respiratory infections. Biomed Chromatogr 2015; 29:1783-90.

154. Sebastian A, Iqbal SA, Colthurst J, Volk SW, Bayat A. Electrical stimulation enhances epidermal proliferation in human cutaneous wounds by modulating p53-SIVA1 interaction. J Invest Dermatol 2015; 135:1166-74. 
Table 1. Common volatile organic compounds produced by bacteria associated with cutaneous wound and surgical site infections

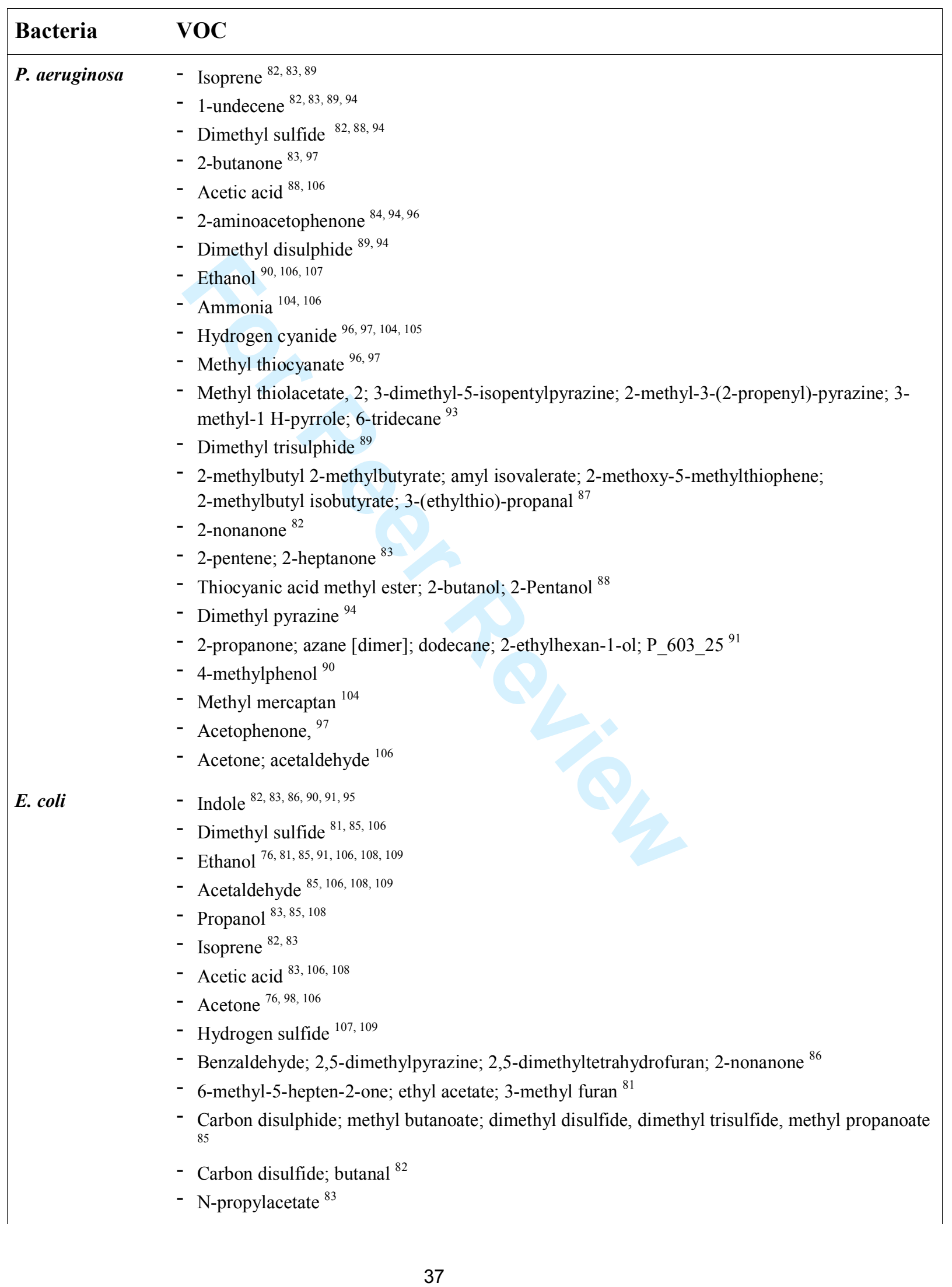


- 2-methylbutanol; 3-methylbutanol ${ }^{95}$

- Heptan-2-one; nonan-2-one ${ }^{76}$

- Methyl cyclohexane; carbon dioxide; pentafluoropropionamide; Dimethylether ${ }^{98}$

- Decan-1-ol; Octan-1-ol ${ }^{91}$

- Formaldehyde; methyl mercaptan ${ }^{107}$

- ammonia $^{109}$

S. aureus

- Ethanol ${ }^{87,106}$

- Acetic acid ${ }^{87,90}$

- Acetaldehyde ${ }^{87,106}$

- Acetone ${ }^{83,90,106}$

- Dimethyl disulfide ${ }^{83,95}$

- Ammonia 106, 107

- 3-methylbutanal; 2-methylpropanal ${ }^{87}$

- 1,1,2,2-tetrachloroethane; dimethyl trisulfide ${ }^{83}$

- Isovaleric acid; 2-methylbutyric acid; isobutyric acid; 1-hydroxy-2-propanone; 3-hydroxy-2-butanone ${ }^{94}$

- 2-tridecenone ${ }^{95}$

- Butanol $^{90}$

- Dimethyl sulfide ${ }^{106}$

MRSA - 2-heptanone; 1,4-dichlorobenzene ${ }^{83}$

S. pyogenes

E. faecalis $\quad$ - Ammonia ${ }^{107}$

S. epidermidis - 3-methyl-1-butanol; 2-methylbutanal; 3-methylbutanoic acid ; 2-methylbutanoic acid ${ }^{80}$

- Ammonia; acetone ${ }^{107}$

VOC - volatile organic compound; P. aeruginosa - Pseudomonas aeruginosa; E. coli Escherichia coli; S. aureus - Staphylococcus aureus; MRSA - methicillin resistant staphylococcus aureus; S. pyogenes - Streptococcus pyogenes; E. faecalis - Enterococcus faecalis; S. epidermidis - Staphylococcus epidermidis. 
Table 2. Unique and shared VOCs between bacteria

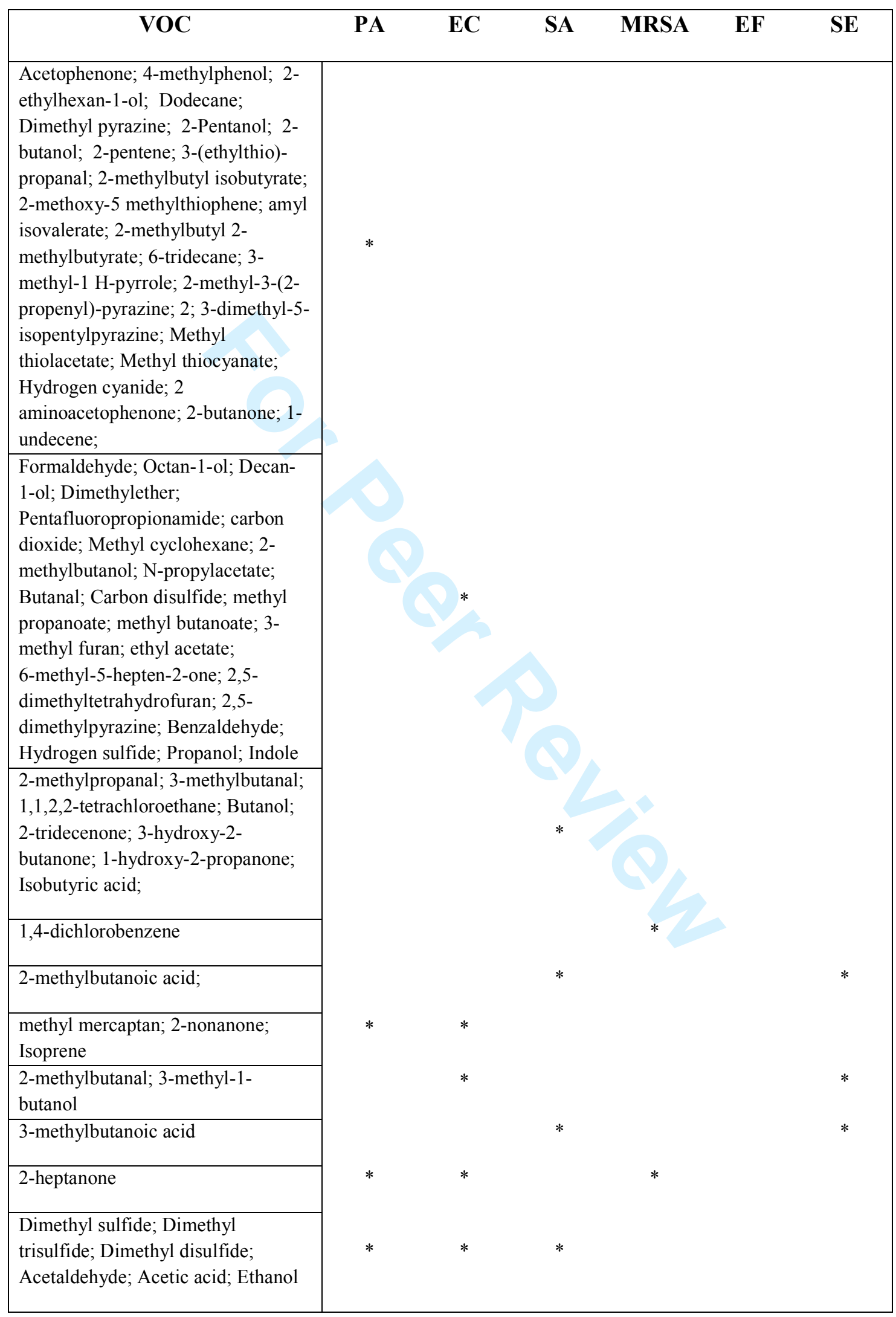


VOC - volatile organic compound; PA - Pseudomonas aeruginosa; EC - Escherichia coli;

SA - Staphylococcus aureus; MRSA - methicillin resistant staphylococcus aureus; SP -

Streptococcus pyogenes; EF - Enterococcus faecalis; SE - Staphylococcus epidermidis. 


\section{Figure Legend}

Figure 1. Volatile organic compound sampling techniques. Spider diagram outlining the common volatile organic compound sampling techniques including their advantages and limitations. VOC - volatile organic compound; GC- gas chromatography; SPME - solid phase micro-extraction; TD - thermal desorption.

Figure 2. Volatile organic compound analytical techniques. Spider diagram outlining the common volatile organic compound analytical techniques including their advantages and limitations. ToF - time of flight; GC-gas chromatography; MS - mass spectrometry; VOC volatile organic compound; SIFT-MS - Selected ion flow tube-mass spectrometry; IMR-MS Ion molecule reaction mass spectrometry; SESI-MS - Secondary electrospray ionisation-mass spectrometry; PTR-MS - Proton transfer reaction-mass spectrometry; IMS - ion mobility spectrometry; MCC - multi capillary columns.

Figure 3. Common volatile organic compounds produced and emitted from skin. Volatile organic compounds in skin are produced by interactions between the secretions from sebaceous, apocrine and eccrine glands and bacteria. Volatile organic compounds detected can be affected by environmental factors. VOC-volatile organic compound.

Figure 4. Volatile organic compounds emitted bodily sites. Volatile organic compounds emitted from the human body vary dependent on site. 


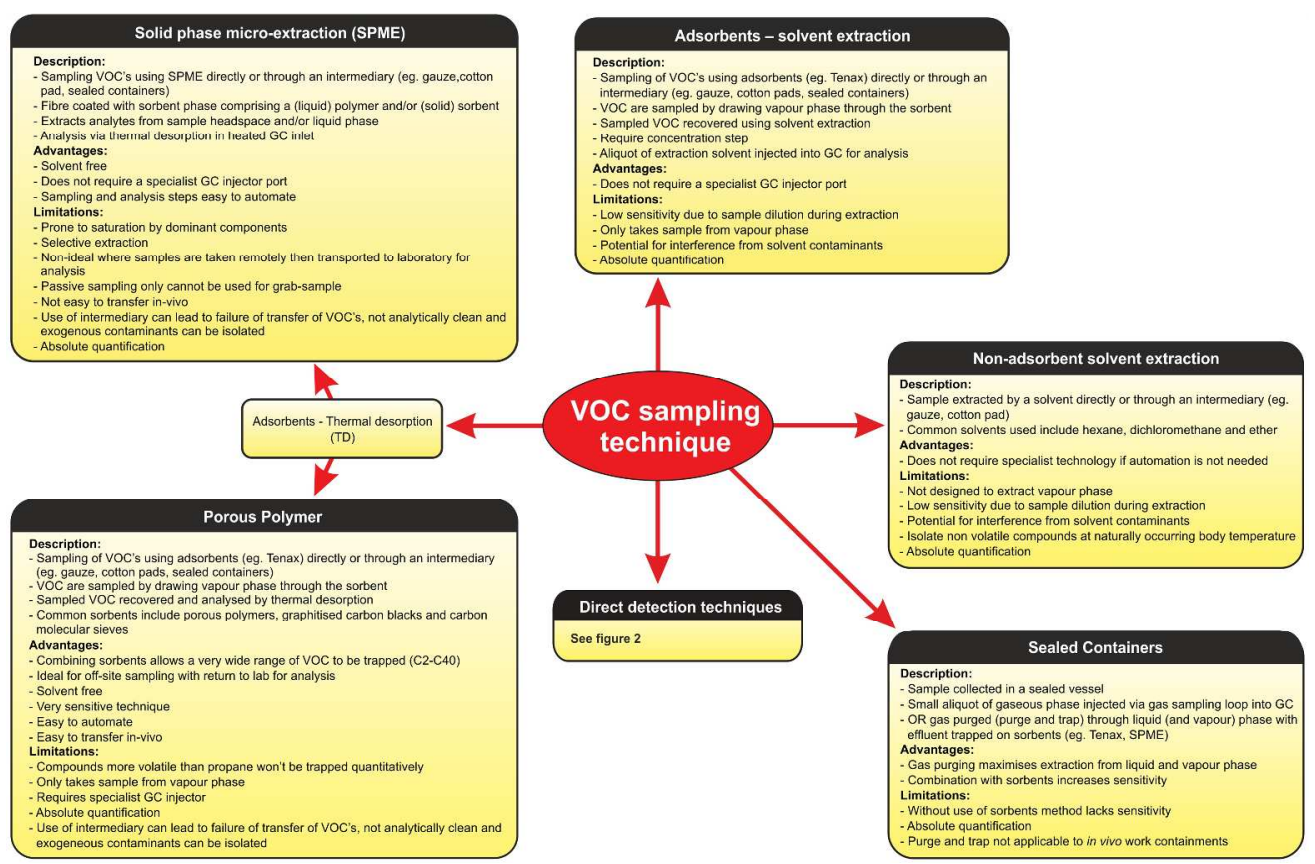

Figure 1. Volatile organic compound sampling techniques. Spider diagram outlining the common volatile organic compound sampling techniques including their advantages and limitations. VOC - volatile organic compound; GC- gas chromatography; SPME - solid phase micro-extraction; TD - thermal desorption.

$297 \times 194 \mathrm{~mm}(300 \times 300 \mathrm{DPI})$ 


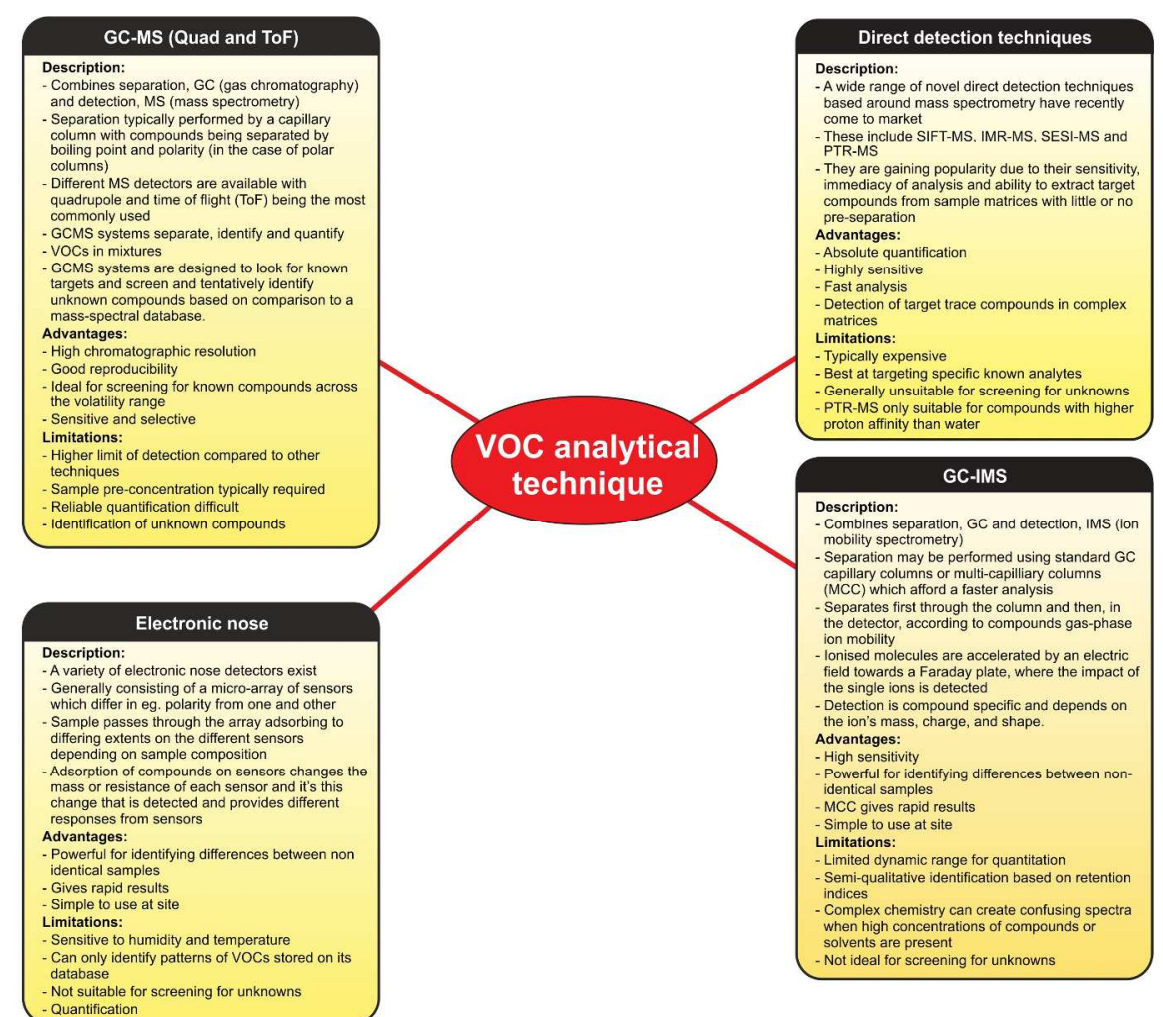

Figure 2. Volatile organic compound analytical techniques. Spider diagram outlining the common volatile organic compound analytical techniques including their advantages and limitations. ToF - time of flight; GCgas chromatography; MS - mass spectrometry; VOC - volatile organic compound; SIFT-MS - Selected ion flow tube-mass spectrometry; IMR-MS - Ion molecule reaction mass spectrometry; SESI-MS - Secondary electrospray ionisation-mass spectrometry; PTR-MS - Proton transfer reaction-mass spectrometry; IMS - ion mobility spectrometry; MCC - multi capillary columns.

$257 \times 199 \mathrm{~mm}(300 \times 300$ DPI) 

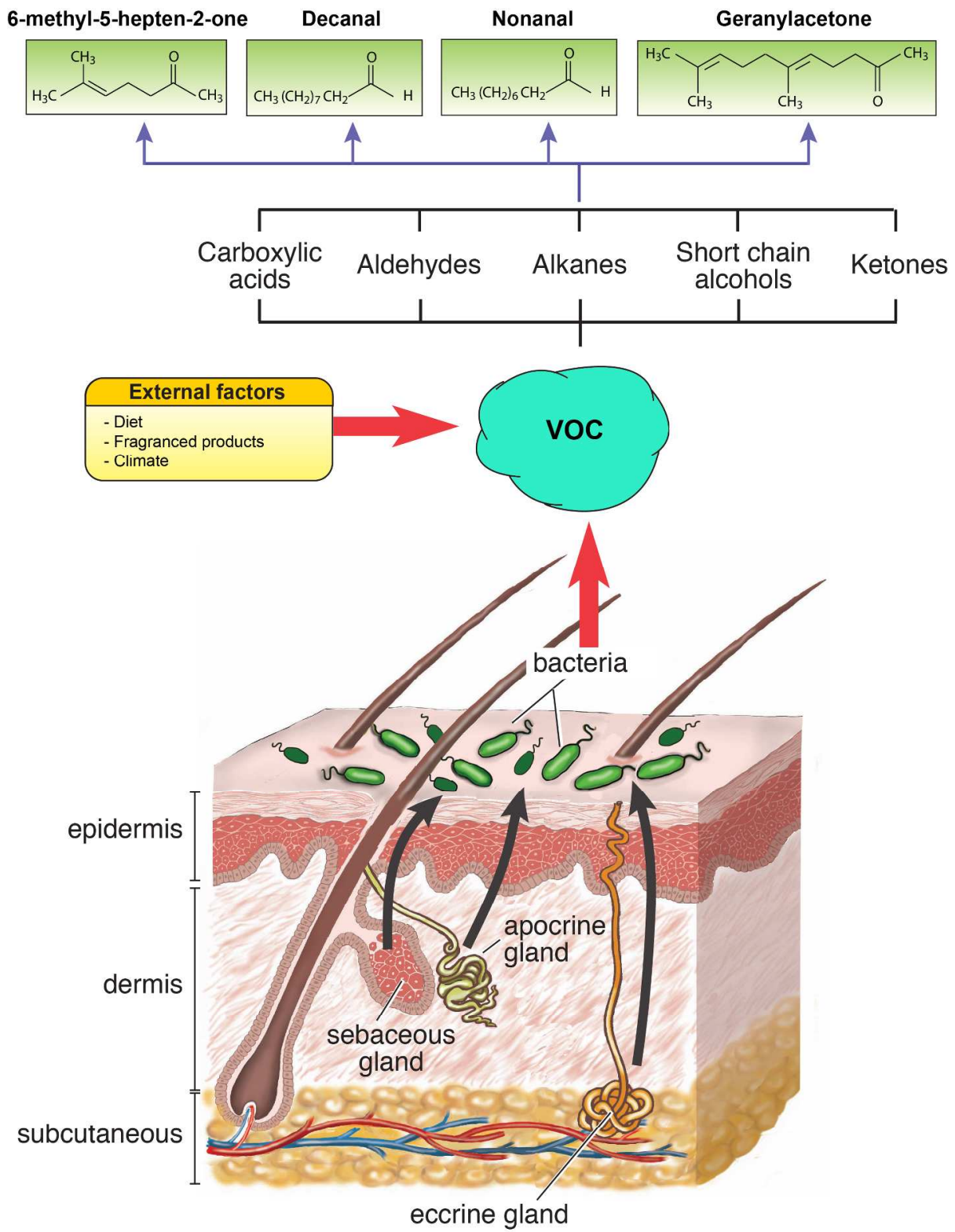

Figure 3. Common volatile organic compounds produced and emitted from skin. Volatile organic compounds in skin are produced by interactions between the secretions from sebaceous, apocrine and eccrine glands and bacteria. Volatile organic compounds detected can be affected by environmental factors. VOC - volatile organic compound.

$$
223 \times 291 \mathrm{~mm}(300 \times 300 \mathrm{DPI})
$$


Figure 4. Volatile organic compounds emitted bodily sites. Volatile organic compounds emitted from the human body vary dependent on site.

\section{$207 \times 168 \mathrm{~mm}(300 \times 300 \mathrm{DPI})$}

